Cite this: Phys. Chem. Chem. Phys., 2014, 16, 2090

Received 22nd October 2013, Accepted 25th November 2013

DOI: $10.1039 / c 3 c p 54914 c$

www.rsc.org/pccp

\title{
Harvesting UV photons for solar energy conversion applications $\dagger$
}

\author{
Mateusz Wielopolski, ${ }^{\text {a }}$ Katharine E. Linton, ${ }^{b}$ Magdalena Marszałek, ${ }^{c}$ Murat Gulcur, ${ }^{\text {b }}$ \\ Martin R. Bryce*b and Jacques E. Moser*a
}

\begin{abstract}
We report the synthesis and characterization of five new donor- $\pi$-spacer-acceptor dye molecules with a diphenylamine donor, fluorene-1,2,5-oxadiazole spacers and a range of acceptor/anchor groups (carboxylic acid 1, cyanoacrylic acid $\mathbf{2}$ and 3, alcohol $\mathbf{4}$ and cyano 5) to facilitate electron injection from the excited dye into the $\mathrm{TiO}_{2}$ photoanode in dye-sensitized solar cells (DSSCs). Detailed photophysical studies have probed the dyes' excited state properties and revealed structure-property relationships within the series. Density functional theory (DFT) and time dependent DFT (TDDFT) calculations provide further insights into how the molecular geometry and electronic properties impact on the photovoltaic performance. A special feature of these dyes is that their absorption features are located predominantly in the UV region, which means the dye-sensitized $\mathrm{TiO}_{2}$ is essentially colorless. Nevertheless, DSSCs assembled from 1 and 2 exhibit photovoltaic power conversion efficiencies of $\eta=1.3$ and $2.2 \%$, respectively, which makes the dyes viable candidates for low-power solar cells that need to be transparent and colorless and for applications that require enhanced harvesting of UV photons.
\end{abstract}

\section{Introduction}

Interfacial electron transfer between semiconductor nanoparticles and molecular adsorbates has been the subject of intense research activities in the past few decades. ${ }^{1}$ In terms of solar energy conversion, the semiconductor-liquid junction solar cell is established as a very promising approach for solar energy conversion and different strategies have been proposed to generate electrical energy from sunlight. For instance, direct collection of light by the semiconductor is feasible when the photonic energy exceeds the energy gap between the valence band and the conduction band of the semiconducting material. In such a case, an electron is promoted from the valence band to the conduction band leaving a positively charged hole behind. Then, usually the hole migrates to the semiconductor/solution interface where it oxidizes a redox-active species in solution.

\footnotetext{
${ }^{a}$ Photochemical Dynamics Group, Institute of Chemical Science and Engineering; École Polytechnique Fédérale de Lausanne, CH-1015 Lausanne, Switzerland. E-mail: mateusz.wielopolski@epfl.ch

${ }^{b}$ Department of Chemistry, Durham University, Durham DH1 3LE, UK. E-mail:m.r.bryce@durham.ac.uk

${ }^{c}$ Laboratory for Photonics \& Interfaces, Institute of Chemical Science and Engineering, École Polytechnique Fédérale de Lausanne, CH-1015 Lausanne, Switzerland

$\dagger$ Electronic supplementary information (ESI) available: Experimental details of materials, instruments and methods employed, representation of optimized geometries, dipole moment vectors and oxidized state orbitals. See DOI: 10.1039/c3cp54914c
}

In contrast, the electron moves away from the interface towards the electrode and an external circuit is set up. On the way to the counter electrode its free energy can be partially extracted, whereas after reaching the counter electrode it is captured by the oxidized redox-active molecule. Importantly, the net chemical reaction in such an arrangement is nil, since every oxidation process at the interface has its counterpart in an interfacial reduction reaction. ${ }^{2}$

For semiconductor materials that can absorb significant portions of the solar spectrum (bandgaps: 1-2 eV) such a direct energy conversion strategy may be considered very efficient. Unfortunately, many of these materials with suitable bandgaps easily undergo destructive hole-based reactions or react with water or oxygen to generate electrically insulating barrier layers.,

On the other hand, materials that are kinetically resistant to photocorrosion often exhibit relatively large bandgaps. One of the conditions for efficient solar energy conversion, however, is the absorption of the high-energy visible portion of the solar spectrum, i.e. light of 400 to $700 \mathrm{~nm}$ wavelengths. Hence, wide-bandgap semiconducting materials such as anatase $\mathrm{TiO}_{2}$ $\left(E_{\mathrm{BG}}=3.2 \mathrm{eV}\right.$, absorption onset $\lambda=380 \mathrm{~nm}$ ), for instance, can be converted into efficient visible-light absorbers by coating them with colored dye molecules. ${ }^{5}$ In such materials, light absorption results in the promotion of an electron from the highest occupied molecular orbital (HOMO) to the lowest unoccupied molecular orbital (LUMO) of the dye. Provided there is efficient electronic coupling between the dye and the semiconductor, the created high-energy electron may be injected into the conduction 
band of $\mathrm{TiO}_{2}$, from where it is transported away to a dark electrode and is able to perform electrical work. This process leaves the dye in its oxidized bleached form and its regeneration to the light-absorbing ground state occurs upon reacting with a solution-phase reductant. The solution species then diffuses to the dark electrode, where it can combine with an electron to complete the circuit. ${ }^{6}$

To date, many different technologies, which utilize the abovementioned principles for direct conversion of solar light to electric energy, coexist and compete with each other. Particular examples are crystalline silicon, semiconductor (e.g., GaAs)-based cells, thinfilm (e.g., CdTe) solar cells, organic bulk heterojunction (BHJ) solar cells and dye-sensitized solar cells (DSSCs). ${ }^{7}$ Among them, the DSSCs have been considered most promising due to their unique biomimetic operating principles.

Briefly, DSSC devices comprise: (i) a transparent conducting oxide substrate, (ii) a mesoporous semiconductor (predominately $\mathrm{TiO}_{2}$ ) film sensitized with dye molecules, (iii) an electrolyte layer containing a redox couple, and (iv) a counter electrode. After absorption of sunlight the photosensitizer is excited into a higher energy state, from which the photoexcited electron is injected into the conduction band of the $\mathrm{TiO}_{2}$. After percolation through the thin mesoscopic semiconductor film, the injected electrons are collected by the conducting substrate and flow into the external circuit. A crucial component in this process is the dye sensitizer. Presently, organic sensitizers for DSSCs fall into two main categories: metal-polypyridyl complexes ${ }^{8}$ and metal-free organic dyes. ${ }^{9}$ DSSCs based on ruthenium(II)polypyridyl complexes usually show high photovoltaic efficiencies in the range of 10 to $11 \%$ due to their wide absorption from the visible to the near-infrared (NIR) regime of the solar spectrum. On the other hand, pure metal-free organic dyes generally possess relatively narrow spectral response within the 400 and $700 \mathrm{~nm}$ range with lower efficiencies. Presently, only a few metal-free organic sensitizers are capable of achieving more than $9 \%$ photovoltaic efficiency in combination with the classical iodide electrolyte. Moreover, achieving appropriate device stabilities is still a great challenge. The major advantages of organic dyes compared to ruthenium complexes are lower material costs and their tunable spectral response and band gaps, arising from the flexibility for systematic structural modifications using relatively straightforward synthetic procedures. Most of these pure organic sensitizers employ an electron donor$\pi$-bridge-electron acceptor $(\mathrm{D}-\pi-\mathrm{A})$ chemical architecture. ${ }^{10}$ Owing to the absorption properties of the dyes, the dyesensitized $\mathrm{TiO}_{2}$ films usually exhibit a yellow to dark red color and are scarcely transparent. As mentioned above, incorporating dyes with high extinction coefficients in the visible part of the solar spectrum is a prerequisite to achieve good lightharvesting properties and high photovoltaic efficiencies. Thereby, transparency of the device may be desirable but not essential. Nonetheless, many applications exist which do not require the highest solar energy conversion efficiencies, but for which transparency is a crucial factor. In this context, lowpower display technologies, which may be implemented onto the windshields of cars or airplanes, could certainly benefit
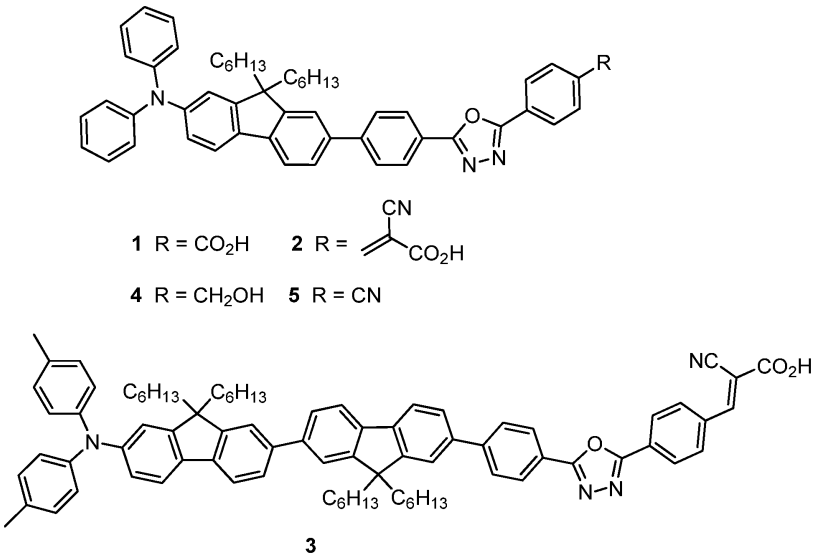

Chart 1 Structures of the dye molecules used in this work.

from transparent power modules. In a similar fashion, clear solar cells could readily power wristwatches directly from the glass crystal instead of from built-in solar batteries, which currently limits the industry's freedom of design. Going even further, if the clearness is due to a shift of the absorption features to the UV region, the cells could be advantageous for applications in environments with enhanced UV irradiation such as outer space. One can certainly find many more examples, where colorless batteries may provide a viable solution for the power supply of devices, which do not necessarily require high conversion efficiencies but have to rely on transparency.

On that account, in this publication we present a novel class of $\mathrm{D}-\pi-\mathrm{A}$ dye molecules with (diphenylamino)fluorene electron donating moieties, diphenyl-oxadiazole $\pi$-spacers and various electron acceptors/anchoring groups (Chart 1). Their absorption features are located in the UV region and would not necessarily suggest significant DSSC activities. Nevertheless, solar cell devices assembled from 1 and 2 exhibit photovoltaic power conversion efficiency values of $\eta=1.28$ and $2.19 \%$, respectively, which makes the dyes viable candidates for transparent low-power solar cells and for applications that require enhanced harvesting of UV photons. An extensive photophysical investigation combined with molecular modeling studies has revealed the impact of the subtle structural differences of the dyes on their electronic properties. Photovoltaic measurements were conducted to test the photocurrent efficiencies and relate them to the dye architecture. In particular, laser spectroscopic techniques establish the singlet excited state characteristics of the dyes in solution and the charge injection and charge recombination dynamics on $\mathrm{TiO}_{2} \cdot{ }^{11,12}$ The insights gained into the structure-dependent electron transfer behavior, together with the molecular modeling and photovoltaic studies, help to explain the high conversion efficiencies and may suggest how to improve them further.

\section{Experimental section}

Full details on the experimental section including film preparation, laser studies, device fabrication, $I-V /$ IPCE measurements and complete synthetic procedures are given in the ESI. $\dagger$ 


\section{Results and discussion}

\section{Molecular design and synthesis}

The dye molecules 1-5 (Chart 1) comprise donor diarylamine units and spacer fluorene ${ }^{13}$ and oxadiazole ${ }^{13}$ units which are known to possess excellent thermal and chemical stabilities. A variety of substituents/anchoring units are attached to the terminal phenyl ring, namely carboxylic acid (1), cyanoacrylic acid (2 and 3), alcohol (4) and cyano (5). The syntheses of the dyes are based on procedures described previously for analogs which did not contain an anchoring unit attached to the terminal phenyl ring. ${ }^{13}$ The additional fluorenyl unit in 3 was incorporated to probe the effects on the spectral response of a more extended $\pi$-system in the core of the molecule. The synthetic procedures for 1, 2, 4 and 5 are shown in Schemes 1 and 2. The spectroscopic and analytical data which confirm the molecular structures of 1-5 are presented in the ESI. $\dagger$

\section{Photophysical investigation}

Fig. 1 shows the absorption spectra of the investigated dyes, 1, 2 and 3 in $0.1 \mathrm{mM}$ tert-butanol/acetonitrile $(1: 1 \mathrm{v} / \mathrm{v})$ solutions and on $5 \mu \mathrm{m}$ thick $\mathrm{TiO}_{2}$ films. In solution, two broad overlapping maxima are found for all three dyes. In accordance with

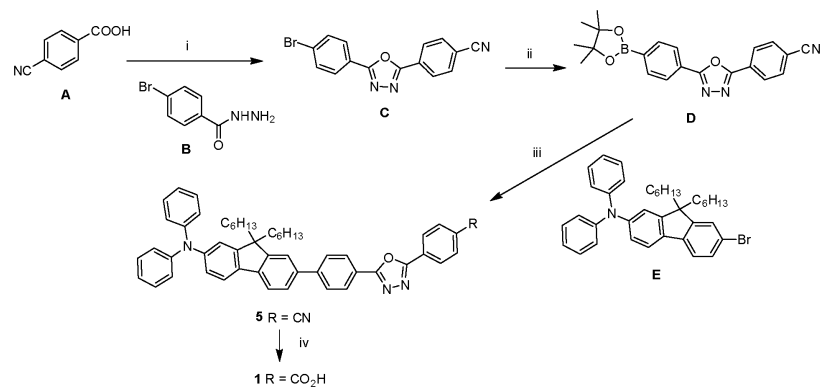

Scheme 1 Synthesis of dyes 1 and 5. Reagents, conditions and yields: (i) TBTU, THF, DIPEA, $20{ }^{\circ} \mathrm{C}, 24 \mathrm{~h}$, then $\mathrm{POCl}_{3}$, reflux $12 \mathrm{~h}, 16 \%$; (ii) $\mathrm{B}_{2} \mathrm{pin}_{2}$, $\left[\mathrm{PdCl}_{2}\right.$ (dppf)], KOAc, DMF, $80{ }^{\circ} \mathrm{C}, 15 \mathrm{~h}, 51 \%$; (iii) $\left[\mathrm{PdCl}_{2}\left(\mathrm{PPh}_{3}\right)_{2}\right], \mathrm{NaOH}$ (aq), $\mathrm{THF}, 65{ }^{\circ} \mathrm{C}, 45 \%$; (iv) $\mathrm{KOH}$ (aq), $\mathrm{EtOH} / \mathrm{H}_{2} \mathrm{O}$, reflux, $15 \mathrm{~h}$, then $\mathrm{HCl}$ (aq), 57\%.

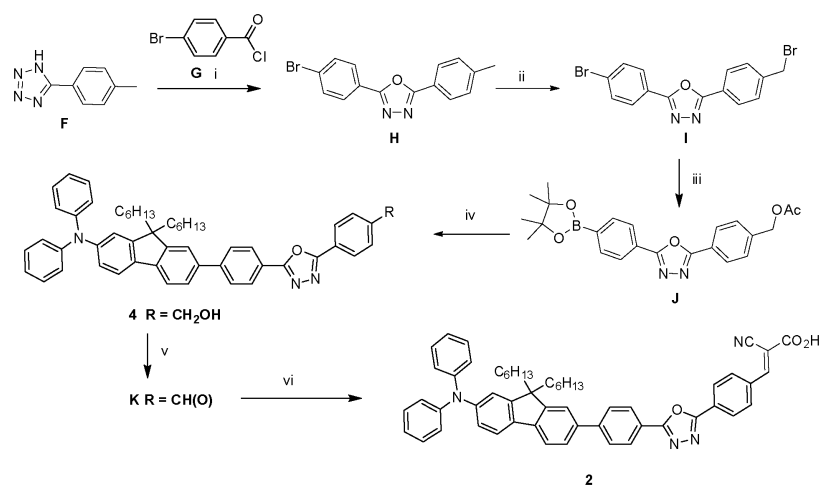

Scheme 2 Synthesis of dyes 2 and $\mathbf{4}$. Reagents, conditions and yields: (i) pyridine, reflux, $72 \mathrm{~h}, 57 \%$; (ii) NBS, benzoyl peroxide, 1,2-dichloroethane, $70{ }^{\circ} \mathrm{C}, 15 \mathrm{~h}, 48 \%$; (iii) $\mathrm{B}_{2} \mathrm{pin}_{2}$, [ $\mathrm{PdCl}_{2}$ (dppf)], KOAc, DMF, $80{ }^{\circ} \mathrm{C}, 15 \mathrm{~h}, 48 \%$; (iv) $\mathrm{E},\left[\mathrm{PdCl}_{2}\left(\mathrm{PPh}_{3}\right)_{2}\right], \mathrm{NaOH}(\mathrm{aq}), \mathrm{THF}, 65^{\circ} \mathrm{C}, 76 \%$; (v) PCC, DCM, $20{ }^{\circ} \mathrm{C}, 1 \mathrm{~h}$, $60 \%$; (vi) cyanoacetic acid, $\mathrm{NH}_{4} \mathrm{OAc}, \mathrm{AcOH}$, reflux, $15 \mathrm{~h}, 50 \%$.

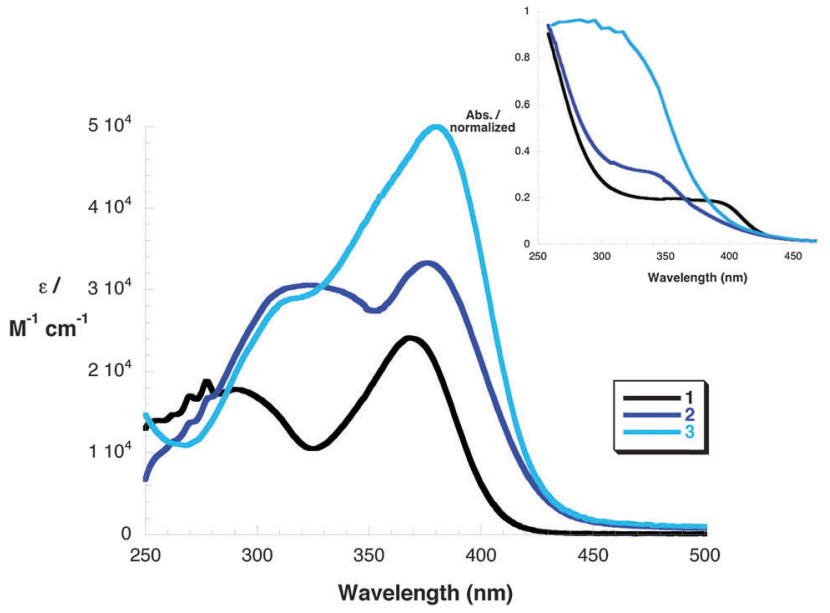

Fig. 1 Absorption spectra of 1, 2 and 3 in a $t \mathrm{BuOH} / \mathrm{ACN}(1: 1$ mixture) $0.1 \mathrm{mM}$ solution. Inset: Absorption spectra of $\mathbf{1}, \mathbf{2}$ and $\mathbf{3}$ on $5 \mu \mathrm{m}$ thick $\mathrm{TiO}_{2}$ films with normalized intensities.

the highly $\pi$-conjugated donor-acceptor type chemical architecture these two maxima correspond to $\pi-\pi^{*}$ charge transfer (CT) excitations within the delocalized and overlapping $\pi$-system of diphenylamine (DA)-fluorene (FL) and the anchoring moieties. The CT character of the excitations has also been confirmed by TDDFT calculations (see below). The red-shifts of the absorption edges correspond well with the relative $\pi$-conjugation length of the molecules. Extended conjugation of the cyanoacrylic acid anchoring group in $\mathbf{2}$ and $\mathbf{3}$ shifts the edges of their absorption spectra by nearly $30 \mathrm{~nm}$ to the red as compared with the carboxylic acid terminated 1. Hence, 1 absorbs up to $400 \mathrm{~nm}$, whereas the tails of 2 and 3 extend to $430 \mathrm{~nm}$. Remarkably, the extension of the $\pi$-conjugation length by an additional fluorene unit, when going from 2 to 3 , causes only a slight shift of the absorption maxima to the red by $4 \mathrm{~nm}$. However, the additional fluorene significantly increases the extinction coefficient of 3 . The extinction coefficients amount to $2.3 \times 10^{4} \mathrm{M}^{-1} \mathrm{~cm}^{-1}$, $3.3 \times 10^{4} \mathrm{M}^{-1} \mathrm{~cm}^{-1}$ and $5.0 \times 10^{4} \mathrm{M}^{-1} \mathrm{~cm}^{-1}$ for 1,2 and 3 , respectively.

To study the applicability in photovoltaic devices, the dyes were adsorbed on $5 \mu \mathrm{m}$ thick transparent $\mathrm{TiO}_{2}$ films. The inset of Fig. 1 shows the corresponding absorption spectra after $16 \mathrm{~h}$ dye loading on $\mathrm{TiO}_{2}$. The spectral changes as compared with bare $\mathrm{TiO}_{2}$ corroborate the adsorption of the dyes onto the semiconductor surface. For instance, 1 exhibits a significant red-shift of its absorption edge by almost $30 \mathrm{~nm}$ due to solidstate interactions on the $\mathrm{TiO}_{2}$ surface. In 2 and 3 , on the other hand, the absorption spectrum is rather blue-shifted with a shoulder developing between 360 and $315 \mathrm{~nm}$. This makes the film nearly colorless while assuring strong interactions due to the binding modalities of the cyanoacrylic acid acceptor. ${ }^{14}$ Remarkably, in 3 the differences in extinction coefficients as compared with 2 are retained after the absorption onto $\mathrm{TiO}_{2}$.

Femtosecond and nanosecond time-resolved spectroscopic techniques were employed to probe the dynamics of the photoinduced charge transfer processes in solution and as adsorbed on the $\mathrm{TiO}_{2}$ surface. The two molecules $\mathbf{4}$ and $\mathbf{5}$ were included 
in the time-resolved solution studies as references. Among these, 5 bears a cyano anchoring group, which exhibits only very weak electron accepting properties, whereas the hydroxylic moiety in $\mathbf{4}$ entirely lacks acceptor properties. The binding to $\mathrm{TiO}_{2}$ was found to be negligible for both 4 and 5. Accordingly, the spectroscopic investigation of these two molecules was limited to solution studies, where photoexcitation results in the population of the singlet excited states.

As seen from the electronic structure of the frontier orbitals (see below) the two different anchoring groups lead to a variation of the LUMOs of 4 and 5. In particular, in 4 the LUMO and the LUMO +1 are delocalized throughout the entire structure lacking orbital coefficients on the $\mathrm{OH}$-terminus. In contrast, the electron withdrawing effect of the cyano-group in 5, promotes a spatial localization of the LUMOs on the anchoring part and a decoupling from the HOMO. Due to this donor-acceptor structure in $\mathbf{5}$, the singlet excited state formation is associated with a charge shift from the electron donating part to the electron accepting part. The result is a stable intramolecular radical ion pair with the positive and negative charges localized on the DA and the anchoring moieties, respectively. Importantly, the DA radical cation is spectrally active ${ }^{15}$ and its spectral fingerprint in solution is used to identify the formation and deactivation of the oxidized state of the remaining dyes on $\mathrm{TiO}_{2}$. It should also be noted that the formation of such decoupled polarons (radical ions) suggests that the low-energy polaron absorptions in the gap should be observed, as well. However, due to the strongly delocalized nature of the $\pi$-systems, these features are masked by the rather broad excited state absorption.

In $\mathbf{4}$, on the other hand, the singlet-excited state formation results from $\pi-\pi^{*}$ transitions within the DA and fluorene orbitals of a strongly delocalized nature, hence, lacking a radical ion pair character. In line with this hypothesis, the transient absorption spectrum of a solution of $\mathbf{4}$ mainly derives from features of local excitations of the DA/fluorene backbone (see theoretical studies) and resembles typical fluorene excited state absorptions. ${ }^{16}$ The singlet excited state in $\mathbf{4}$ forms immediately after laser excitation and is identified by a small shoulder at $480 \mathrm{~nm}$ and a broad maximum between 550 and $700 \mathrm{~nm}$ (Fig. 2 - top). The deactivation occurs following first order kinetics with a rate of $k_{\mathrm{SD}}=4.6 \times$ $10^{9} \mathrm{~s}^{-1}$. The transient absorption spectrum of 5 resembles at very early stages comparable excited state features, i.e. a shoulder at $480 \mathrm{~nm}$ and a broad maximum between 550 and $700 \mathrm{~nm}$, as found in 4. These, however, transform on the time-scale of approximately $1 \mathrm{ps}\left(k_{\mathrm{CS}}=1.5 \times 10^{12} \mathrm{~s}^{-1}\right)$ into new absorptions with a broad maximum between 470 and $580 \mathrm{~nm}$ and a sharp peak at $670 \mathrm{~nm}$ (Fig. 2 - bottom) suggesting another process as a deactivation channel of the photoinduced absorption. In line with the electron accepting features of the cyano group and the resulting localization of the LUMO, the low-energy excitation of the fluorene moieties promotes in a second step the charge shift from the DA-localized HOMO to the LUMO on the CN-terminus. Hence, we attribute the newly developed absorption to the radical cation of the DA moiety $\left(\mathrm{DA}^{\bullet+}\right)$. Such HOMO to LUMO charge transfer transitions, which result in the formation of intramolecular radical ion pairs, are common for this type of
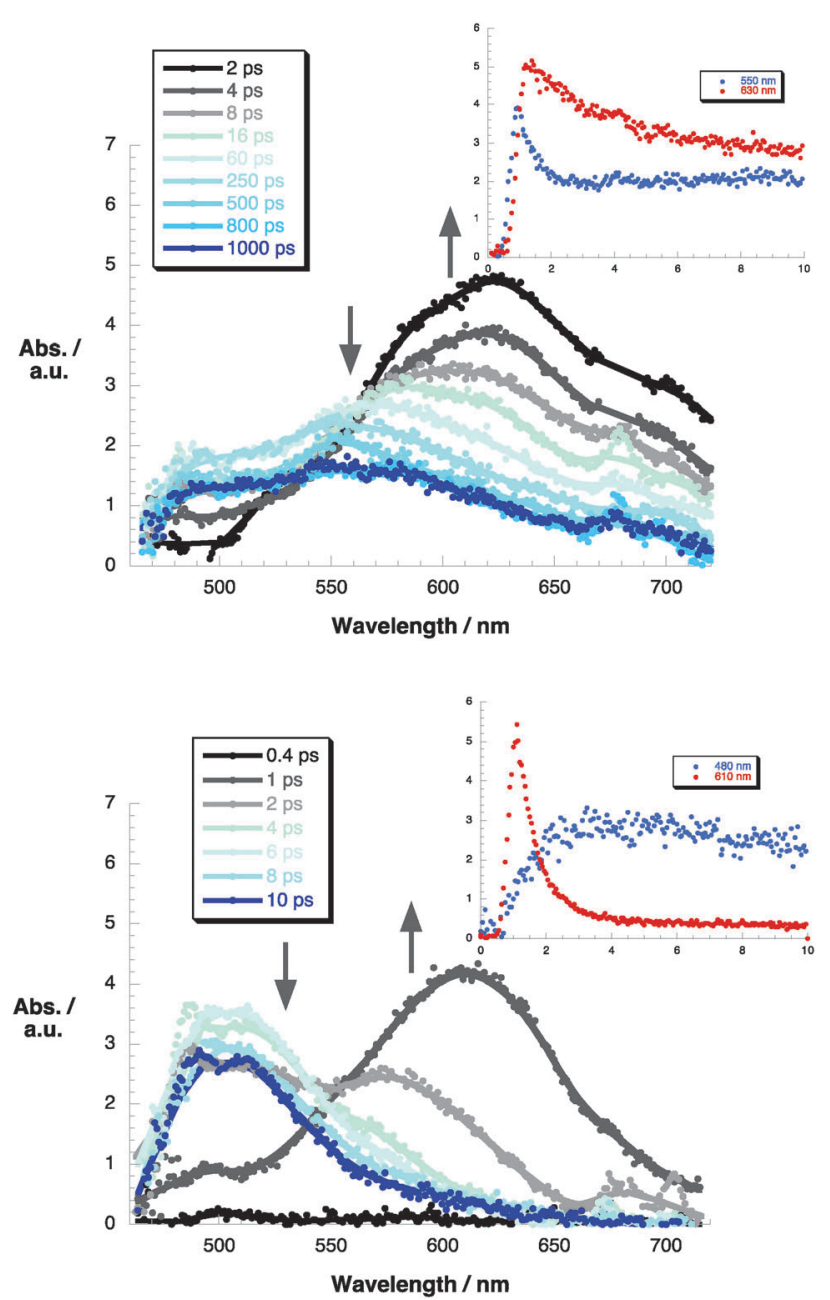

Fig. 2 Transient absorption spectra obtained upon femtosecond pulsed laser excitation ( $\lambda_{\text {exc }}=400 \mathrm{~nm}$ ) of $\mathrm{tBuOH} / \mathrm{ACN}(1: 1) 0.1 \mathrm{mM}$ solutions of 4 (top) and $\mathbf{5}$ (bottom) with several pump-probe time delays at room temperature. Insets: corresponding time profiles illustrating the kinetics of the signals at different wavelengths.

organic donor-acceptor dyes ${ }^{17}$ and were confirmed by our TD-DFT studies. The DA radical cation features decay with very fast kinetics $\left(k_{\mathrm{SD}}=4.3 \times 10^{10} \mathrm{~s}^{-1}\right)$ on a time-scale of less than $100 \mathrm{ps}$ in solution. It should be mentioned that the broad shape of the radical cation signature stems from the fact that the donor conjugates into the bridge, which allows for an excellent spatial delocalization of the positive charge upon oxidation of the DA nitrogen atom. This is particularly obvious when scrutinizing the electrostatic potentials of the oxidized species of the dyes (Fig. 7).

The femtosecond transient absorption spectra of the solutions of 1, 2 and 3 (Fig. 3) exhibit spectral fingerprints, which are comparable to those seen in the reference systems $\mathbf{4}$ and $\mathbf{5}$. Thus, in $\mathbf{2}$ and $\mathbf{3}$ with the strong cyanoacrylic acid acceptor the DA/fluorene excited state features transform into the corresponding radical ion pair features on a time scale of $<2 \mathrm{ps}$ $\left(k_{\mathrm{CS}}=1.2 \times 10^{12} \mathrm{~s}^{-1}\right.$ for 2 and $k_{\mathrm{CS}}=1.7 \times 10^{12} \mathrm{~s}^{-1}$ for 3$)$. The latter decays with dynamics following first order kinetics $\left(k_{\mathrm{SD}}=5.1 \times 10^{10} \mathrm{~s}^{-1}\right.$ for 2 and $k_{\mathrm{SD}}=5.0 \times 10^{10} \mathrm{~s}^{-1}$ for 3$)$ with a 

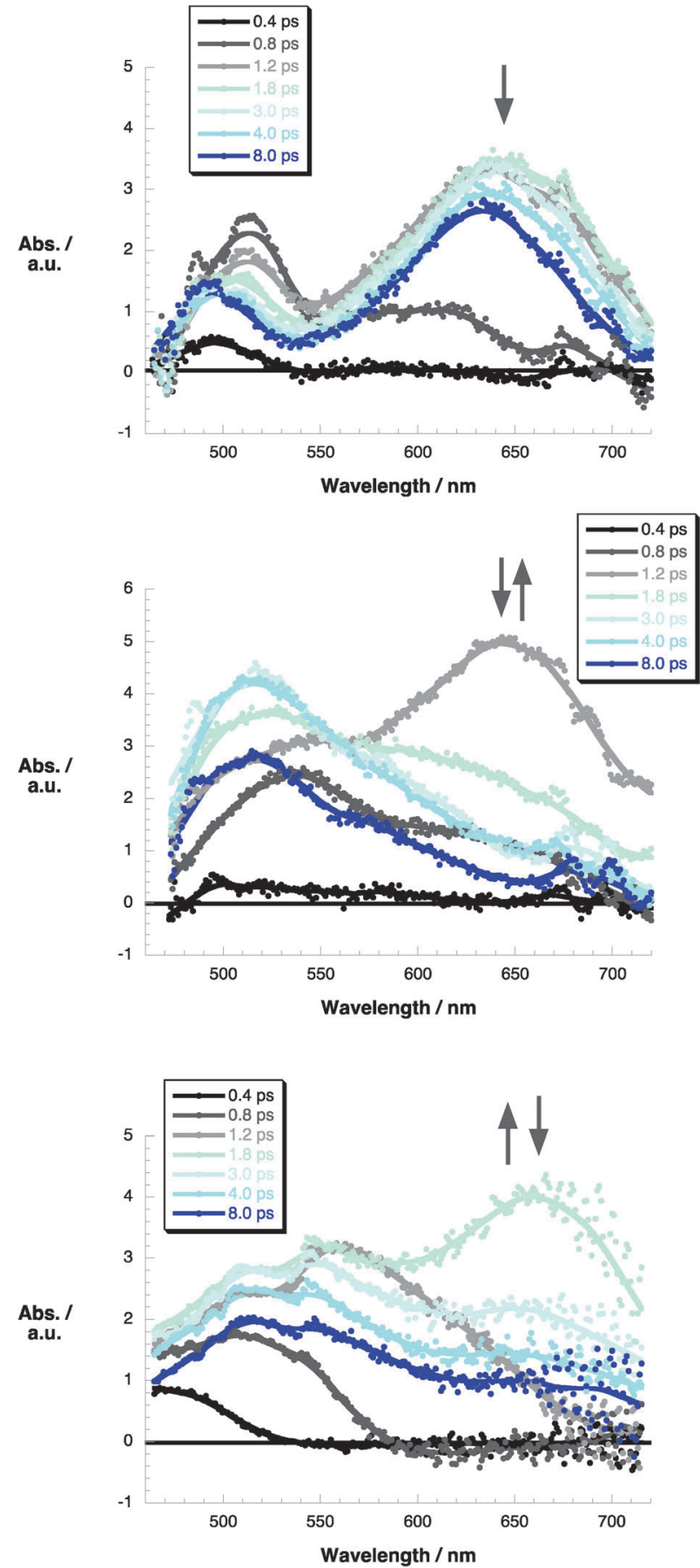

Fig. 3 Transient absorption spectra obtained upon femtosecond pulsed laser excitation ( $\lambda_{\text {exc }}=400 \mathrm{~nm}$ ) of $t \mathrm{BuOH} / \mathrm{ACN}(1: 1) 0.1 \mathrm{mM}$ solutions of $\mathbf{1}$ (top), $\mathbf{2}$ (middle) and $\mathbf{3}$ (bottom) with several pump-probe time delays at room temperature.

rate similar to $\mathbf{5}$. In $\mathbf{1}$, on the other hand, the singlet features vanish rather slowly $\left(k_{\mathrm{SD}}=5.8 \times 10^{9} \mathrm{~s}^{-1}\right)$ and the corresponding radical cation signature does not evolve.

In the presence of an electron acceptor such as $\mathrm{TiO}_{2}$ the situation changes significantly. Given the fact that the binding through the cyanoacrylic acid anchoring group provides sufficient electronic coupling for charge injection into the conduction band of the semiconductor, this process occurs extremely rapidly in 2 and 3. In fact, immediately after $0.6 \mathrm{ps}$ the signature of the oxidized state of both dyes is present in their spectra (Fig. 4 - top). In the first 300 ps this very fast charge injection is followed by a decay ( $\tau_{1 / 2}=168 \mathrm{ps}$ for 2 and $\tau_{1 / 2}=47 \mathrm{ps}$ for 3 ) to approximately $60 \%$ of the initial intensity, which then remains

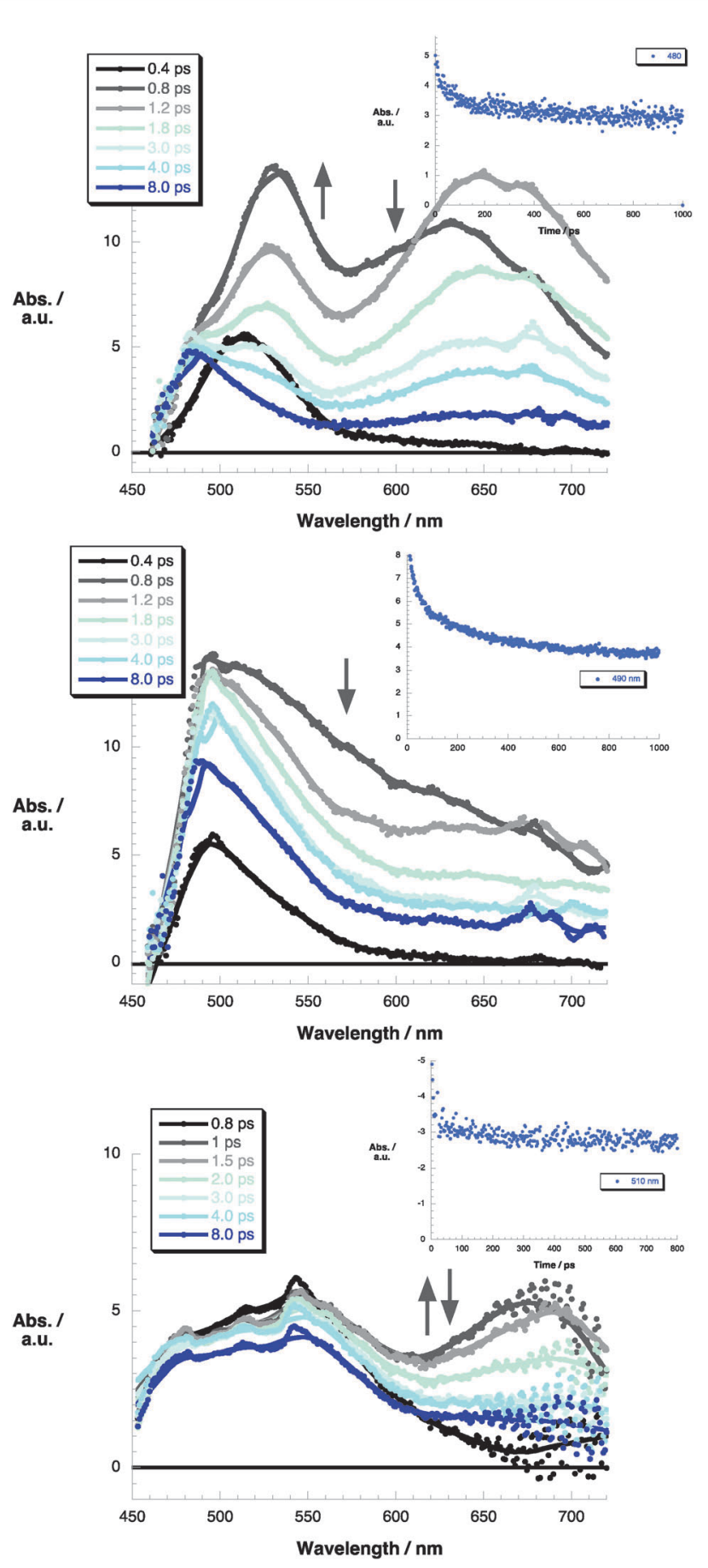

Fig. 4 Transient absorption spectra obtained upon femtosecond pulsed laser excitation $\left(\lambda_{\text {exc }}=400 \mathrm{~nm}\right.$ ) of 1 (top), 2 (middle) and 3 (bottom) adsorbed on $5 \mu \mathrm{m}$-thick $\mathrm{TiO}_{2}$ mesoporous films with several pump-probe time delays at room temperature. Insets: corresponding time profiles illustrating the kinetics of the signals at different wavelengths. 
constant on the time-scale of our experimental setup (1100 ps). Assuming that the relatively high pulse energies generate more than one electron per particle during one pulse, due to the relatively short distance between the donor center and the anchoring group, some of these electrons will rapidly recombine with the oxidized dye (intraparticle electron-hole recombination $)^{18}$ whereas others diffuse in the $\mathrm{TiO}_{2}$. Hence, at such high carrier concentrations only $60 \%$ of the generated electrons diffuse into the $\mathrm{TiO}_{2}$, which leads to long-lived charge separated states and is reflected in the persistence of the spectral signals of the radical ion pair species.

The electron injection in $\mathbf{1}$ occurs slightly slower due to the lower electron affinity of the carboxylic acid anchor as compared with the cyanoacrylic acid. Unlike in $\mathbf{2}$ and $\mathbf{3}$, the formation of the singlet excited state is clearly identified as the initial state in $\mathbf{1}$ (Fig. 4 - bottom). The excited state then transforms on a time-scale of 8 ps into the features of the oxidized DA cation. The fate of the radical cation signal, however, is comparable to the trends established for dyes 2 and 3, where the fast electron injection is governed by the effective coupling of the cyanoacrylic acid to $\mathrm{TiO}_{2}$.

To probe the kinetics of the charge recombination between electrons injected into $\mathrm{TiO}_{2}$ and the oxidized states of the dyes nanosecond flash photolysis measurements have been employed. In these experiments the excitation energies are kept at very low levels as compared with the foregoing femtosecond studies allowing the injection of less than one electron per pulse per nanoparticle. Under such conditions, charge carrier recombination in each nanoparticle volume compartment involves a single electron-hole pair. Notably, if diffusion of carriers from one particle to the other is neglected in the sub-ms time-scale, this reaction can be described by a first order rate law. ${ }^{18}$ This allows for probing the regeneration of the dyes' ground state by back-electron transfer from $\mathrm{TiO}_{2}$, which now takes place in the $\mu$ s-ms timescale.

As expected, the characteristic features of the oxidized state, namely the broad absorption between 440 and $580 \mathrm{~nm}$ and the sharper peak around $670 \mathrm{~nm}$ (Fig. 5), evolved equally, confirming the stable nature of the oxidized species of the dyes on $\mathrm{TiO}_{2}$. Remarkably, the signals decay with relatively slow kinetics, i.e. $k_{\mathrm{CR}}=8.3 \times 10^{2} \mathrm{~s}^{-1}$ for $1, k_{\mathrm{CR}}=1.3 \times 10^{3} \mathrm{~s}^{-1}$ for 2 and $k_{\mathrm{CR}}=1.8 \times$ $10^{4} \mathrm{~s}^{-1}$ for 3 (Table 1). The fact that in the oxidized state the dihedral angles between the FLs and the adjacent phenyl rings decrease in $\mathbf{1}$ and $\mathbf{2}$ suggests that photoinduced charge injection is connected to a slight gain in enthalpy due to increased conjugation by planarization of the $\pi$-system (see molecular modeling). This, in turn, will result in the stabilization of the oxidized states of the dyes leading to remarkably long recombination times in the range of milliseconds in $\mathbf{1}$ and $\mathbf{2}$ and tens of microseconds in 3 . The significantly faster recombination in $\mathbf{3}$, on the other hand, complies well with the fact that in $\mathbf{3}$ the corresponding dihedral angles do not decrease and, hence, a comparable gain in enthalpy to $\mathbf{1}$ and $\mathbf{2}$ is not present. Notably, although the variations of the dihedral angles by values between 2 and 4 degrees may seem rather subtle, considering the fact that they have been established from calculations under
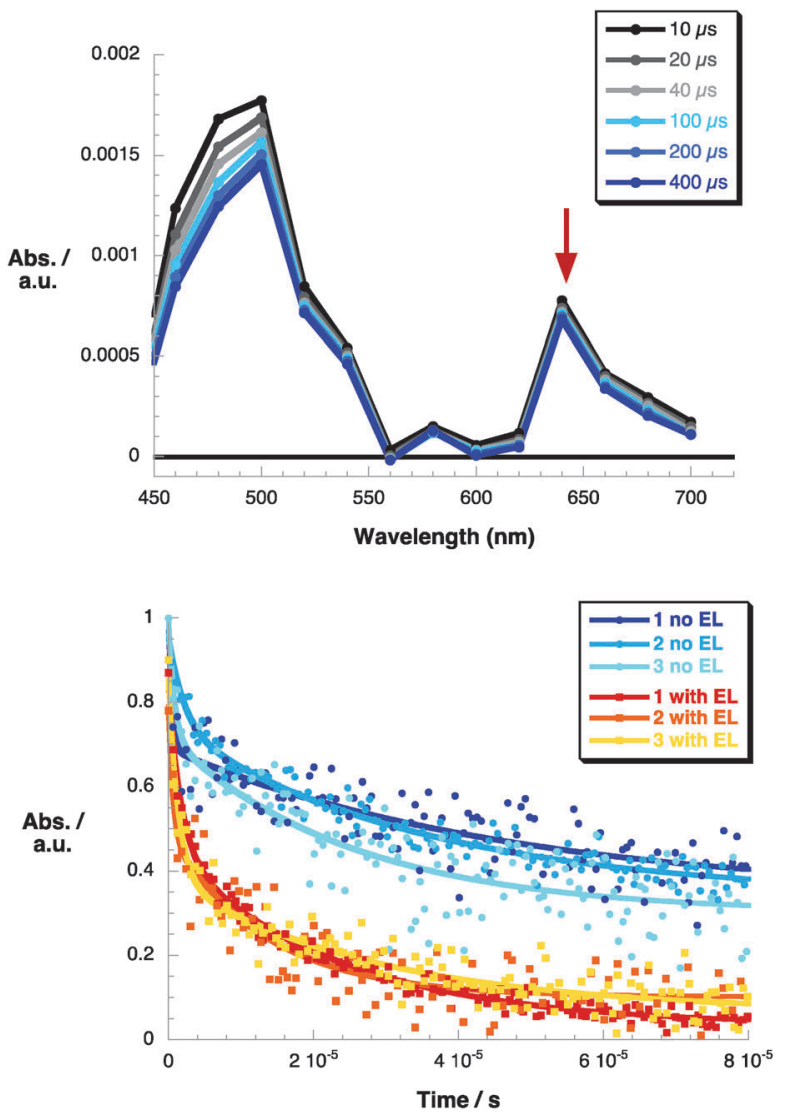

Fig. 5 Representative transient absorption spectra obtained upon nanosecond flash photolysis ( $\lambda_{\text {exc }}=420 \mathrm{~nm}$ ) of 2 (top) and the corresponding normalized time profiles of the signals at $600 \mathrm{~nm}$ of 1, 2 and 3 (bottom), which compare the deactivation kinetics in the absence of an electrolyte (EL) and in its presence as recorded on $5 \mu \mathrm{m}$ thick $\mathrm{TiO}_{2}$ with several time delays at room temperature.

Table 1 Summary of the rate constants and half-lifetimes $\left(\tau_{1 / 2}\right)$ obtained for all different processes, i.e. singlet excitation $\left(k_{S}\right)$, charge separation $\left(k_{\mathrm{CS}}\right)$, charge injection $\left(k_{\mathrm{Cl}}\right)$, singlet deactivation $\left(k_{\mathrm{SD}}\right)$, charge recombination $\left(k_{C R}\right)$ and dye regeneration $\left(k_{\mathrm{DR}}\right)$ for all dyes 1-5 in $0.1 \mathrm{mM} \mathrm{tBuOH/}$ ACN $(1: 1 \mathrm{v} / \mathrm{v})$ solution and on $5 \mu \mathrm{m} \mathrm{TiO}_{2}$ films as obtained by femtosecond and nanosecond transient absorption measurements with 400 and $420 \mathrm{~nm}$ light excitation, respectively

\begin{tabular}{|c|c|c|c|c|c|}
\hline & 1 & 2 & 3 & 4 & 5 \\
\hline \multicolumn{6}{|c|}{$t \mathrm{BuOH} / \mathrm{ACN}$} \\
\hline$k_{\mathrm{S}} / \mathrm{s}^{-1}-$ & $2.5 \times 10^{12}$ & $3.6 \times 10^{12}$ & $1.4 \times 10^{12}$ & $3.8 \times 10^{12}$ & $2.6 \times 10^{12}$ \\
\hline & $0.39 \mathrm{ps}$ & $0.28 \mathrm{ps}$ & $0.70 \mathrm{ps}$ & $0.26 \mathrm{ps}$ & $0.39 \mathrm{ps}$ \\
\hline$k_{\mathrm{CS}} / \mathrm{s}^{-1}-$ & - & $1.2 \times 10^{12}$ & $1.7 \times 10^{12}$ & - & $1.2 \times 10^{12}$ \\
\hline$\tau_{1 / 2}$ & & $0.7 \mathrm{ps}$ & $0.6 \mathrm{ps}$ & & $0.7 \mathrm{ps}$ \\
\hline$k_{\mathrm{SD}} / \mathrm{s}^{-1}-$ & $5.8 \times 10^{9}$ & $5.1 \times 10^{10}$ & $5.0 \times 10^{10}$ & $4.6 \times 10^{9}$ & $4.3 \times 10^{10}$ \\
\hline$\tau_{1 / 2}$ & $172 \mathrm{ps}$ & $19 \mathrm{ps}$ & $20 \mathrm{ps}$ & $217 \mathrm{ps}$ & $23 \mathrm{ps}$ \\
\hline
\end{tabular}

$\begin{array}{lllll}\mathrm{TiO}_{2} & & & & \\ k_{\mathrm{CI}} / \mathrm{s}^{-1}- & 1.8 \times 10^{12} & 4.1 \times 10^{12} & 3.1 \times 10^{12} & - \\ \tau_{1 / 2} & 0.55 \mathrm{ps} & 0.24 \mathrm{ps} & 0.32 \mathrm{ps} & \\ k_{\mathrm{CR}} / \mathrm{s}^{-1}- & 8.3 \times 10^{2} & 1.3 \times 10^{3} & 1.8 \times 10^{4} & - \\ \tau_{1 / 2} & 1.20 \mathrm{~ms} & 770 \mu \mathrm{s} & 56 \mu \mathrm{s} & \end{array}$

$\mathrm{TiO}_{2}$ with EL

$\begin{array}{lllll}k_{\mathrm{DR}} / \mathrm{s}^{-1}-7.6 \times 10^{9} & 4.1 \times 10^{9} & 6.1 \times 10^{9} & - & - \\ \tau_{1 / 2} & 10 \mathrm{~ns} & 24 \mathrm{~ns} & 17 \mathrm{~ns} & \end{array}$ 
vacuum, their effects on the $\mathrm{TiO}_{2}$ surface, where intermolecular solid-state interactions restrict conformational changes to a much higher extent than in solution, become much more significant regarding the stabilities of the oxidized dye species.

The addition of the $\mathrm{Z960}$ redox electrolyte solution promotes a ten-fold decrease of the lifetime of the $\mathrm{DA}^{\bullet+}$ signal (Table 1), which confirms that the long lifetimes of the oxidized species of the dyes are governed mainly by the dyes' structural differences and their changes upon photoexcitation. The reason for this is that in the presence of a redox electrolyte solution dye regeneration by electrons from the iodide competes with the charge recombination processes mentioned above. The regeneration process occurs much faster than the charge recombination by back electron transfer from $\mathrm{TiO}_{2}$. Furthermore, as seen from the dye regeneration rate constants $\left(k_{\mathrm{DR}}\right)$ shown in Table 1, they do not reveal significant differences among each other, which suggests that the regeneration process is fairly independent of the dye structure. Hence, the chemical architecture significantly impacts the charge recombination and the amount of electrons present in $\mathrm{TiO}_{2}$ after injection.

\section{Molecular modeling}

To investigate the molecular structures and electronic properties of 1-5, density functional theory (DFT) methods have been employed. All geometries have been optimized using the M062 $\mathrm{X}^{19}$ functional with the $6-31 \mathrm{G}(\mathrm{d})^{20}$ basis set as implemented into the Gaussian $09^{21}$ suite of programs.

Considering the energy-minimized geometries (Fig. S1, ESI $\dagger$ ), the structural differences between the different dyes are rather subtle. Characteristic for all dyes is that the linker between the DA donor and the anchoring group significantly deviates from planarity. In all systems the torsions between the FL unit and the adjacent phenyl rings comprise dihedral angles of 36 to $39^{\circ}$. Hence, these torsions imply not only a spatial but also an electronic decoupling of the donor and acceptor moieties. Such electronic separation of donor and acceptor orbitals (see Fig. 6) gives rise to a permanent dipole moment and a directive vectorial driving force for the electrons to be transferred from the donor to the acceptor. The corresponding dipole moment vectors are shown in Fig. S2 (ESI $\dagger$ ).

Fig. 6 provides a representation of the frontier orbitals of dyes 1-5 including the HOMO - 1 and the LUMO - 1 for comparison. At first glance, the acceptor strength, which corresponds to an increase in electron affinity from the hydroxyl over the carboxyl to the cyano and the cyanoacrylic acid group, is reflected in the extent of localization of electron density of the lowest unoccupied molecular orbitals (LUMOs) on the anchoring termini. Thus, in $\mathbf{4}$ the LUMO is rather delocalized with coefficients reaching into the DA donor. Importantly, no electron density is found on the hydroxyl anchoring part. In contrast, 2 and 3 exhibit strongly localized LUMOs with the highest coefficients on the anchoring parts, whereas electron density of the LUMO +1 orbitals is localized mainly on the spacer between the donor and the acceptor. $\mathbf{1}$ and $\mathbf{5}$ exhibit a comparable localization of electron density on the anchoring parts but to a lesser extent than in 2 and 3 . The LUMO +1 orbitals are delocalized over the entire molecular structure.

The highest occupied molecular orbitals (HOMOs) are identical for all the dyes and are localized on the DA and the FL moiety. They remain invariant upon changing the anchoring groups corroborating the fact that the above-mentioned dihedral angles in the linker moiety electronically decouple the donors

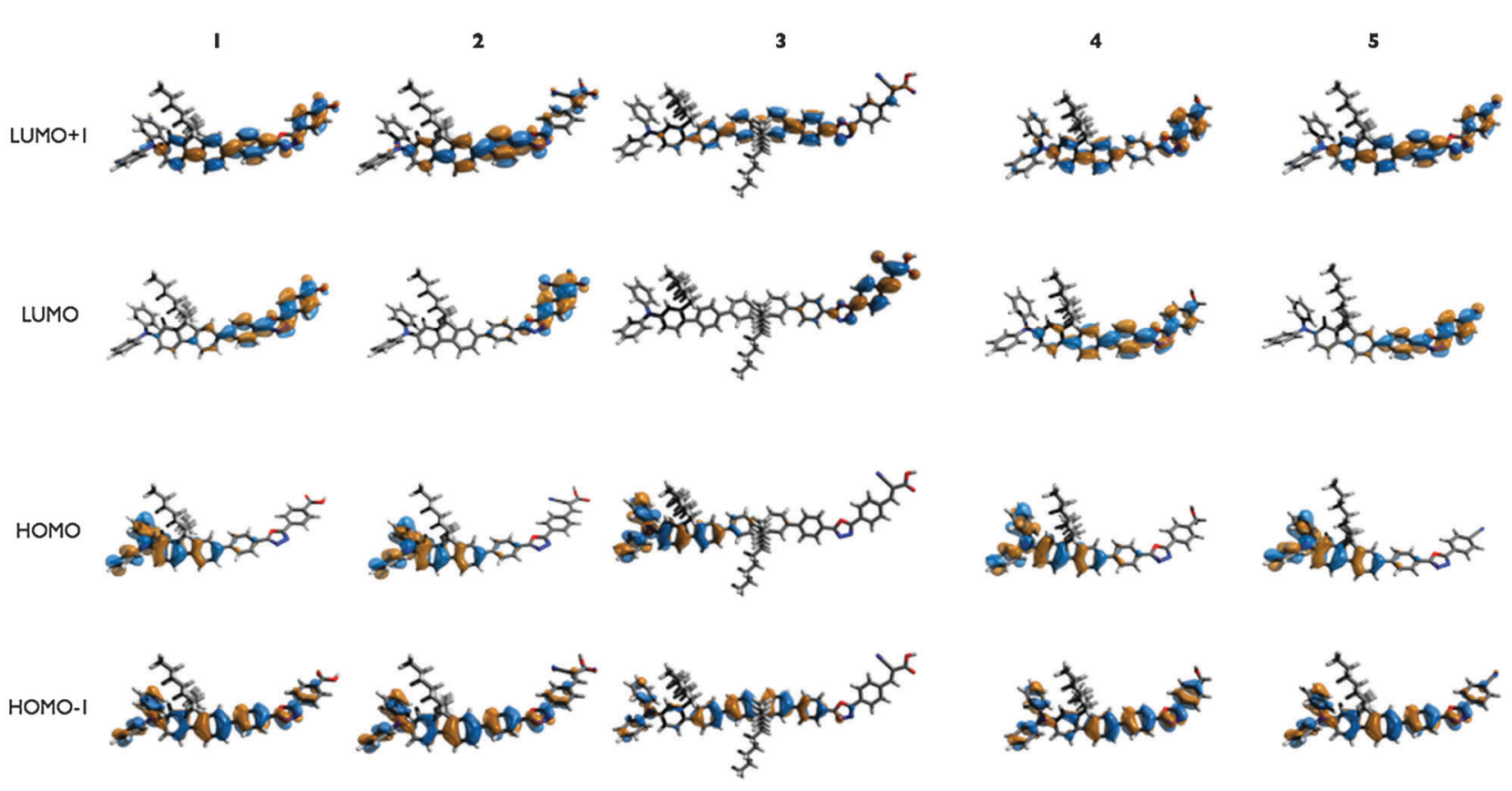

Fig. 6 Representation of the frontier orbitals HOMO - 1 to LUMO + 1 in the neutral state for the dyes 1-5 showing the invariance of the HOMO and the localization of the LUMO in correlation with the electron affinity of the anchoring groups. For consistency, dye 3 diphenylamine replaces di( $p$-tolyl)amine. 
Table 2 M062X energies in eV of the frontier orbitals of 1-5 with the corresponding HOMO-LUMO gaps and wB97XD lowest excited state properties calculated by TD-DFT methods

\begin{tabular}{|c|c|c|c|c|c|}
\hline LUMO + 1 & -0.25 & -0.74 & -0.65 & -2.4 & -0.97 \\
\hline HOMO & -6.1 & -6.1 & -6.1 & -6.1 & -6.0 \\
\hline HOMO - 1 & -7.1 & -7.3 & -7.2 & -7.1 & -6.8 \\
\hline HOMO-LUMO gap & 5.2 & 4.7 & 4.9 & 3.4 & 4.0 \\
\hline Lowest excited state & $\begin{array}{l}E_{\mathrm{n}}: 3.43 \mathrm{eV} \\
\lambda_{\mathrm{exc}}=361 \mathrm{~nm} \\
f=2.08 \\
\mathrm{H} \rightarrow \mathrm{L}+1\end{array}$ & $\begin{array}{l}E_{\mathrm{n}}: 3.42 \mathrm{eV} \\
\lambda_{\mathrm{exc}}=363 \mathrm{~nm} \\
f=2.35 \\
\mathrm{H} \rightarrow \mathrm{L}+1\end{array}$ & $\begin{array}{l}E_{\mathrm{n}}: 3.64 \\
\lambda_{\mathrm{exc}}=341 \mathrm{~nm} \\
f=3.11 \\
\mathrm{H}-1 \rightarrow \mathrm{L} \\
\mathrm{H}-1 \rightarrow \mathrm{L}+1\end{array}$ & $\begin{array}{l}E_{\mathrm{n}}: 3.43 \mathrm{eV} \\
\lambda_{\text {exc }}=361 \mathrm{~nm} \\
f=2.07 \\
\mathrm{H} \rightarrow \mathrm{L}\end{array}$ & $\begin{array}{l}E_{\mathrm{n}}: 3.43 \mathrm{eV} \\
\lambda_{\mathrm{exc}}=361 \mathrm{~nm} \\
f=2.07 \\
\mathrm{H} \rightarrow \mathrm{L}+1\end{array}$ \\
\hline
\end{tabular}

and the anchors from each other. The invariance of the HOMOs is also reflected by their energies as shown in Table 2 . The situation concerning the LUMO energies is different.

In general, the LUMO energies follow the electron affinity of the anchoring group and the increasing spatial localization of the orbital coefficients. In other words, in $\mathbf{4}$, where the electron accepting features of the $\mathrm{OH}$ anchor are negligible, the LUMO is fairly well delocalized and its energy is highest. 2 and 3 comprise the anchoring groups with the highest electron affinity; accordingly the LUMOs are strongly localized and their energies are significantly lower than in the other dyes. The HOMO-LUMO energy gaps follow the same trends. Notably, the energies of $\mathbf{3}$ are slightly higher than of $\mathbf{2}$. This can be explained by the second fluorene moiety of $\mathbf{3}$, which does not contribute to the extension of $\pi$-conjugation as compared with 2 due to the bifluorenyl dihedral angle of $36^{\circ}$. Consequently, increasing the electron affinity of the anchor and, therefore, decoupling the HOMO from the LUMO appear to lower the HOMO-LUMO energy gap by shifting electron density onto the anchor. This not only lowers the energies for singlet-excitation but also creates a directive driving force for electron transfer from the donor to the acceptor. Additionally, the electronic coupling into $\mathrm{TiO}_{2}$ is improved with increasing electron density on the anchoring part, which facilitates the charge injection into $\mathrm{TiO}_{2}$. Obviously, the dihedral angles between the fluorenes and the adjacent phenyls favor the localization of electron density on the anchoring groups. Together with electron-withdrawing anchoring groups a directive HOMO to LUMO singlet excitation will most likely result in a nearly activationless charge injection into $\mathrm{TiO}_{2}$.

To gain insight into the structural changes that evolve upon oxidation we have optimized the geometries of the positively charged species of the dye molecules. It turned out that in the oxidized state the dihedral angles between the fluorene moieties and the adjacent phenyl rings decrease by at least $2^{\circ}$ (Fig. S1, ESI $\dagger$ ). As seen in Fig. S3 (ESI $\dagger$ ), the singly occupied molecular orbitals (SOMOs) of 1, 2, 4 and 5 resemble the HOMO electron density, however, they are significantly more delocalized over the entire molecular structure. In general, this would match the fact that if electron density is removed from the HOMO the electrostatic repulsion to the filled p-orbitals of the electron-rich fluorene and phenyl moieties decreases, which allows for a slightly more planar conformation of the spacer between the donor and the acceptor. This, in turn, enhances the delocalization, which stabilizes the oxidized species. Notably, the electron density of the LUMOs is shifted towards the donor sites as well, which agrees with the slightly decreasing dihedral angles and increasing delocalization. Due to the additional fluorene moiety, the situation is slightly different for 3 , where only the first dihedral angle decreases upon oxidation. As a consequence, the SOMO exhibits the main orbital contributions on the fluorene moieties rather than on the donor sites. Hence, by introducing a second fluorene moiety the oxidation potential of the fluorenes is lowered, which renders them reasonable electron donors as confirmed by the TD-DFT studies. Another effect of the extension of the spacer between the donor and the acceptor by incorporating a bifluorenyl unit is seen when examining the electrostatic potential maps of the oxidized states in Fig. 7. There, the delocalization of the positive charge (red) in the oxidized form of 3 is improved due to the spatial extension of the $\pi$-system. This stabilizes the oxidized state and favors its formation.

Finally, time-dependent DFT (TD-DFT) methods were employed to study the nature of the lowest-energy electronic transitions and determine the orbitals involved. The TD-DFT
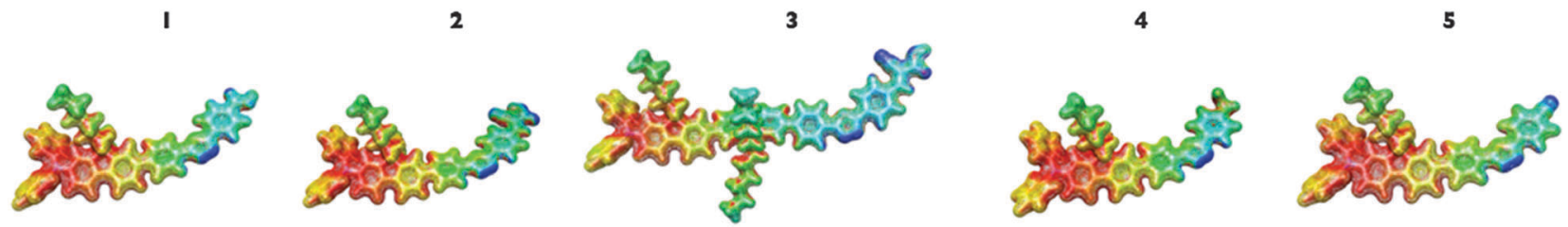

Fig. 7 Mappings of the electrostatic potential (ESP) of the oxidized state of all dyes showing the differences in localization of the positive charge (red). Color code: blue to red: $-0.1 \mathrm{e}^{-}$to $0.1 \mathrm{e}^{-}$. For consistency, for dye 3 diphenylamine replaces di(p-tolyl)amine. 
calculations were conducted on the previously optimized geometries using the $\mathrm{wB}^{\mathrm{B}} \mathrm{7 \textrm {XD } ^ { 2 2 }}$ functional, which is known to include empirical dispersion functions. For each molecule the five lowest excited states have been computed applying the polarizable continuum model ${ }^{23}$ to simulate solvent interactions in dichloromethane. The calculations indicate that the excited states with the lowest energies stem for the most part from HOMO to LUMO + 1 transitions for $\mathbf{1}, \mathbf{2}$, and $\mathbf{5}$, whereas in $\mathbf{4}$ the lowest excited state is ascribed to a HOMO to LUMO excitation. In $\mathbf{3}$, on the other hand, mainly one-electron excitations from the HOMO -1 constitute the lowest excited state (Table 2). As seen from the orbital representations in Fig. 6, the LUMO +1 in 1, 2, 3 and 5 contain significant contributions from the fluorene $\pi$-orbitals. In $\mathbf{4}$, the fluorene $\pi$-system is already involved in the LUMO. Additionally, the HOMO -1 in 3 also comprises coefficients largely on the fluorene moiety. Hence, the TD-DFT calculations confirm that local excitations of the fluorene $\pi$-system will occur instantaneously prior to charge transfer processes from HOMO to the LUMO and obviously mix with them due to the extended $\pi$-conjugated systems of all the dyes. Such a mixing will most likely occur when the fluorene-centered LUMO +1 is energetically higher than the acceptor-centered LUMO. Furthermore, increasing the number of fluorene units as in $\mathbf{3}$ lowers the oxidation potential of the fluorenes and significantly increases the oscillator strength of the lowest excited state in 3. Experimentally, this is reflected in the much higher extinction coefficient of $\mathbf{3}$ as compared with $\mathbf{1}$ and 2 . On the other hand, if the LUMO comprises coefficients on the fluorene moiety as in 4, the singlet excited state will most likely lack a charge transfer character.

In conclusion, the calculations have shown a strong dependence of the excited state properties of the dyes on their electronic structure. By increasing electron affinity of the anchor it is possible to vary the dipole moments and increase the electronic decoupling of the HOMO and the LUMO, which in turn helps to direct the charge transfer towards $\mathrm{TiO}_{2}$. In other words, increasing the localization of the LUMO densities and increasing the electron affinity of the anchoring groups will increase the electronic coupling matrix element to $\mathrm{TiO}_{2}$ and create a vectorial path for the electrons to be transferred from the donor to the acceptor and finally to $\mathrm{TiO}_{2}$. However, as seen from the variations of electron density of the frontier orbitals, the electronic features of the dyes result from a sensitive interplay of the electronic properties of the building blocks, i.e. the electron donor, the $\pi$-spacer and the electron acceptor/ anchoring unit. Hence, even small-scale structural variations may result in significant changes in the charge transfer properties of the dyes and - in a further step - in their photovoltaic performances. Finally, we would like to stress that for these kinds of compounds an analysis of natural transition orbitals would probably provide a more accurate description of the excited states.

\section{Photovoltaic studies}

Dye-sensitized solar cells. The sensitizers 1, 2 and 3 have been tested for their photovoltaic performance in dye sensitized solar cells. Although their absorption spectra overlap with the bandgap energy of $\mathrm{TiO}_{2}(3.2 \mathrm{eV}-387 \mathrm{~nm})$, during standard photovoltaic characterization of the device a remarkable photocurrent reaching
Table 3 Photovoltaic parameters of the devices sensitized with 1, 2 and $\mathbf{3}$ at 1 Sun illumination. Isc stands for the short-circuit photocurrent density, $V_{\text {oc }}$ for the open-circuit voltage, and $\boldsymbol{\eta}$ for the incident light to electricity power conversion efficiency under AM1.5 illumination conditions

\begin{tabular}{lllll}
\hline Dye & $J_{\mathrm{sc}} / \mathrm{mA} \mathrm{cm}^{-2}$ & $V_{\mathrm{oc}} / \mathrm{mV}$ & Fill factor & $\eta / \%$ \\
\hline $\mathbf{1}$ & 2.18 & 752 & 0.79 & 1.28 \\
$\mathbf{2}$ & 4.68 & 671 & 0.76 & 2.19 \\
3 & 1.31 & 581 & 0.73 & 0.58
\end{tabular}

up to $4.7 \mathrm{~mA} \mathrm{~cm}^{-2}$ was recorded (Table 3). The photoanodes used in the experiment consisted of a double layered $\mathrm{TiO}_{2}$ film - an $8 \mu \mathrm{m}$ transparent layer made of $20 \mathrm{~nm}$ sized particles and a $5 \mu \mathrm{m}$ scattering layer made of $400 \mathrm{~nm}$ particles - and they were stained in the dye solutions for $18 \mathrm{~h}$. The coloration (yellowish) was very weak; however 2 appeared to be slightly darker than the other dyes. This translated directly to the efficiency of the photocurrent generation and the overall efficiency of the devices.

In order to investigate the amount of photocurrent generated solely by the dyes and not by the direct absorption of the semiconductor, a set of three types of devices was manufactured: standard DSSCs with photoanodes sensitized with the dyes, and devices where $\mathrm{TiO}_{2}$ was left bare. The $I V$ plots are presented in Fig. 8. The cells with non-sensitized $\mathrm{TiO}_{2}$ yielded in the best case: $J_{\mathrm{sc}}=0.185 \mathrm{~mA} \mathrm{~cm}{ }^{-2}$ with $V_{\mathrm{oc}}=532 \mathrm{mV}$, ff $=0.64$ and overall power conversion efficiency of $0.06 \%$.

The current generated by the non-sensitized device is considerably lower, even when compared with the devices with dyes absorbing in the UV region, which is an indirect proof of the photovoltaic action occurring due to the dye molecules. In order to measure the external quantum efficiencies (IPCE) of the devices yielding rather low currents manifested mainly below $400 \mathrm{~nm}$ we had to increase the sensitivity of our setup and expand the spectral range to $320 \mathrm{~nm}$ (limitation due to the calibration of the spectrum). We did not measure the IPCE for wavelengths longer than $600 \mathrm{~nm}$. The integrated currents obtained from these measurements agree perfectly with the $J_{\mathrm{sc}}$ measured during the standard conditions of $I V$ characterization.

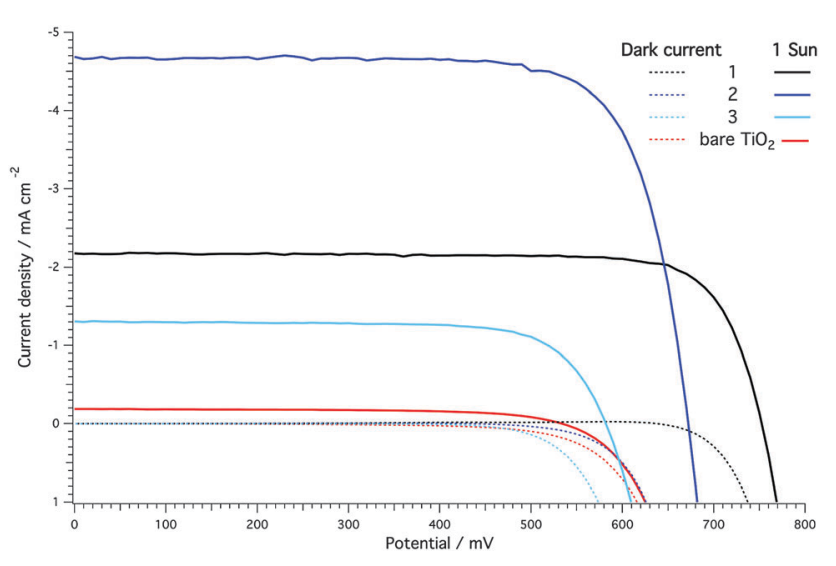

Fig. $8 \mathrm{IV}$ plots of three best performing devices - one with bare $\mathrm{TiO}_{2}$, two others sensitized with $\mathbf{1} \mathbf{2}$ and $\mathbf{3}$, respectively. Solid lines correspond to the measurements done under one Sun illumination (AM1.5), dashed lines dark current measurements. 


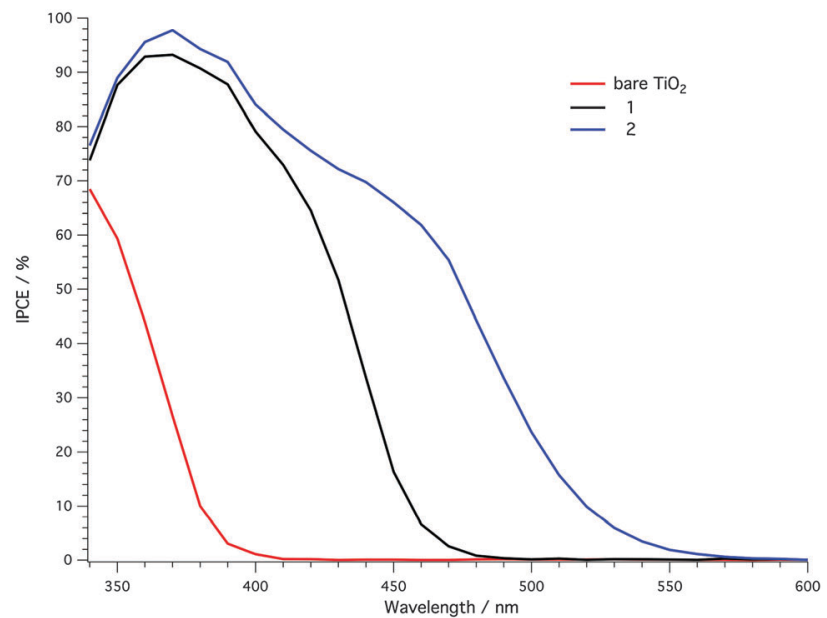

Fig. 9 Incident photon-to-current conversion efficiency (ICPE) plots for devices sensitized with $\mathbf{1}$ (black) and $\mathbf{2}$ (blue) as well as "dummy", nonsensitized devices with $\mathrm{TiO}_{2}$ and electrolyte only (red).

Fig. 9 clearly shows that the contribution from $\mathrm{TiO}_{2}$ to the overall photogenerated current is nearly negligible as compared with the photovoltaic action stemming from the dyes. The absorption spectra are significantly broadened, reaching up to $550 \mathrm{~nm}$ (2), especially when compared to the spectra of the dyes adsorbed on $\mathrm{TiO}_{2}$ (onset $450 \mathrm{~nm}$ ).

\section{Conclusions}

We have designed, synthesized and probed the photophysical properties of a new series of $\mathrm{D}-\pi-\mathrm{A}$ sensitizers. The absorption features of these dyes are located predominantly in the UV region, which means the dye-sensitized $\mathrm{TiO}_{2}$ is essentially transparent. Our results clearly demonstrate that dye molecules 1 and 2, which display power conversion efficiencies of $\eta=1.28$ and $2.19 \%$, respectively, with IPCE values exceeding $90 \%$ at $\lambda=380 \mathrm{~nm}$, are promising candidates for colorless low-power solar cells and for applications that require harvesting of UV photons. Ongoing work aims at enhancing the light harvesting ability in the UV region through molecular engineering of metal-free $\mathrm{D}-\pi-\mathrm{A}$ dye molecules and at improving the theoretical model by employing natural transition orbital theory.

\section{Acknowledgements}

We thank EPSRC for funding for KEL (grants EP/F017375/1 and EP/J501323/1). We thank EC FP7 ITN “FUNMOLS” Project No. 212942 for funding for MG. MW and JEM are grateful to the NCCR MUST, a research instrument of the Swiss National Science Foundation, for generous support.

\section{Notes and references}

1 Y.-X. Weng, Y.-Q. Wang, J. B. Asbury, H. N. Ghosh and T. Lian, J. Phys. Chem. B, 2000, 104, 93.
2 S. G. Yan, L. A. Lyon, B. I. Lemon, J. S. Preiskorn and J. T. Hupp, J. Chem. Educ., 1997, 74, 657.

3 (a) J. M. Rosamilia and B. J. Miller, Electrochem. Soc., 1985, 132, 349; (b) M. S. Wrighton, Acc. Chem. Res., 1979, $12,303$.

4 (a) J. M. Bolts, A. B. Bocarsly, M. C. Palazzotto, E. G. Walton, N. S. Lewis and M. S. Wrighton, J. Am. Chem. Soc., 1979, 101, 1378; (b) M. J. Heben, A. Kumar, C. Zheng and N. S. Lewis, Nature, 1989, 340, 621.

5 (a) P. V. Kamat, Chem. Rev., 1993, 93, 267; (b) G. J. Meyer and P. C. Searson, Interface, 1993, 2, 23; (c) B. A. Parkinson and M. T Spitler, Electrochim. Acta, 1992, 37, 943.

6 (a) A. Hagfeldt and M. Grätzel, Chem. Rev., 1995, 95, 49; (b) M. X. Tan, P. E. Laibinis, S. T. Nguyen, J. M. Kesselman, C. E. Stanton and N. S. Lewis, Prog. Inorg. Chem., 1994, 41, 21. 7 B. O'Regan and M. Grätzel, Nature, 1991, 353, 737.

8 N. Robertson, Angew. Chem., Int. Ed., 2006, 45, 2338.

9 (a) A. Hagfeldt, G. Boschloo, L. Sun, L. Kloo and H. Pettersson, Chem. Rev., 2010, 110, 6595; (b) A. Mishra, M. K. R. Fischer and P. Bäuerle, Angew. Chem., Int. Ed., 2009, 48, 2474.

10 J. N. Clifford, E. Martinez-Ferrero, A. Viterisi and E. Palomares, Chem. Soc. Rev., 2011, 40, 1635.

11 Y. Tachibana, J. E. Moser, M. Grätzel, D. R. Klug and J. R. J. Durrant, Phys. Chem., 1996, 100, 20056.

12 N. J. Cherepy, G. P. Smestad, M. Grätzel and J. Z. Zhang, J. Phys. Chem. B, 1997, 101, 9342.

13 (a) K. T. Kamtekar, C. Wang, S. Bettington, A. S. Batsanov, I. F. Perepichka, M. R. Bryce, J. H. Ahn, M. Rabinal and M. C. Petty, J. Mater. Chem., 2006, 16, 3823; (b) K. E. Linton, A. L. Fisher, C. Pearson, M. A. Fox, L.-O. Palsson, M. R. Bryce and M. C. Petty, J. Mater. Chem., 2012, 22, 11816.

14 Z. S. Wang, Y. Cui, Y. Dan-oh, C. Kasada, A. Shinpo and K. Hara, J. Phys. Chem. C, 2007, 111, 7224.

15 (a) M. Oyama, T. Higuchi and S. Okazaki, Electrochem. Solid-State Lett., 2002, 5, E1; (b) S. Fantacci, F. De Angelis, M. K. Nazeeruddin and M. Grätzel, J. Phys. Chem. C, 2011, 115, 23126; (c) J. R. Pinzón, D. Gasca, S. Gayathri, G. Bottari, T. Torres, D. M. Guldi and L. Echegoyen, J. Am. Chem. Soc., 2009, 131, 7727.

16 C. van der Pol, M. R. Bryce, M. Wielopolski, C. Atienza, D. M. Guldi, S. Filippone and N. Martín, J. Org. Chem., 2007, 72, 6662.

17 (a) S. Haid, M. Marszalek, A. Mishra, M. Wielopolski, J. Teuscher, J.-E. Moser, R. Humphry-Baker, S. M. Zakeeruddin, M. Grätzel and P. Bäuerle, Adv. Funct. Mater., 2012, 22, 1291; (b) M. Katono, T. Bessho, M. Wielopolski, M. Marszalek, J.-E. Moser, R. Humphry-Baker, S. M. Zakeeruddin and M. Grätzel, J. Phys. Chem. C, 2012, 116, 16876.

18 G. Rothenberger, J.-E. Moser, M. Grätzel, N. Serpone and D. K. Sharma, J. Am. Chem. Soc., 1985, 107, 8054.

19 Y. Zhao and D. G. Truhlar, Theor. Chem. Acc., 2008, 120, 215. 20 V. A. Rassolov, J. A. Pople, M. A. Ratner and T. L. Windus, J. Chem. Phys., 1998, 109, 1223.

21 M. J. Frisch, et al., Gaussian Inc., Wallingford, CT, 2009.

22 J.-D. Chai and M. Head-Gordon, Phys. Chem. Chem. Phys., 2008, 10, 6615.

23 J. Tomasi, B. Mennucci and R. Cammi, Chem. Rev., 2005, 105, 2999. 


\section{Journal Name}

\section{ARTICLE}

Citethis: DOI: 10.1039/×0xx00000x

\section{Harvesting UV Photons for Solar Energy Conversion Applications}

Mateusz Wielopolski, ${ }^{*}, \mathrm{a}$ Katharine E. Linton, ${ }^{\mathrm{c}}$ Magdalena Marszałek, ${ }^{\mathrm{b}}$ Murat Gulcur, ${ }^{\mathrm{c}}$ Martin R. Bryce, ${ }^{*, \mathrm{c}}$ and Jacques E. Moser*,

Received 00th January 2012,

Accepted 00th J anuary 2012

DOI: $10.1039 / x 0 \times x 00000 x$

unw.rsc.org/

\section{Supporting Information}

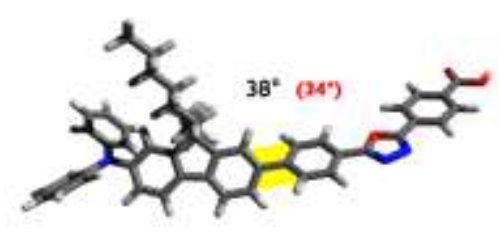

1

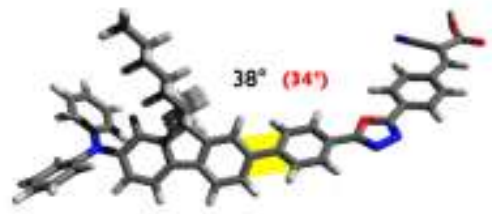

2

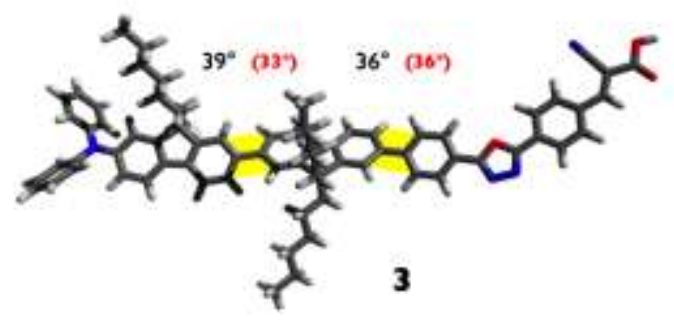

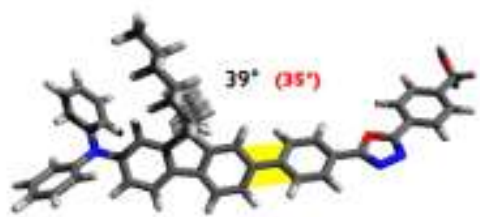

4

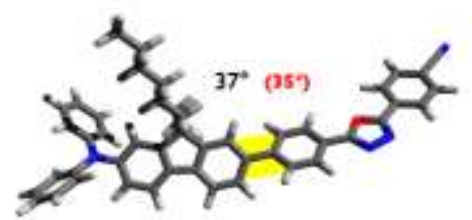

5

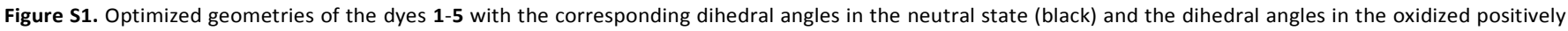
charged conformation (red) as mentioned in the manuscript. For consistency, for dye $\mathbf{3}$ diphenylamine replaces di( $p$-tolyl)amine. 


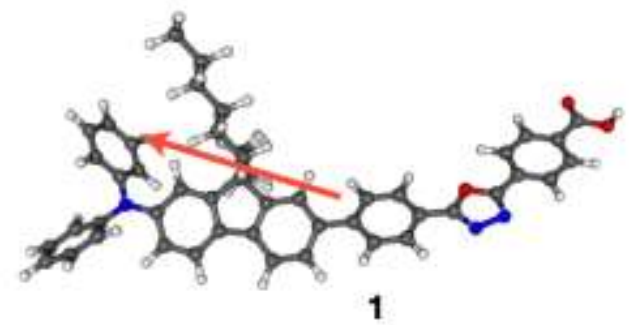

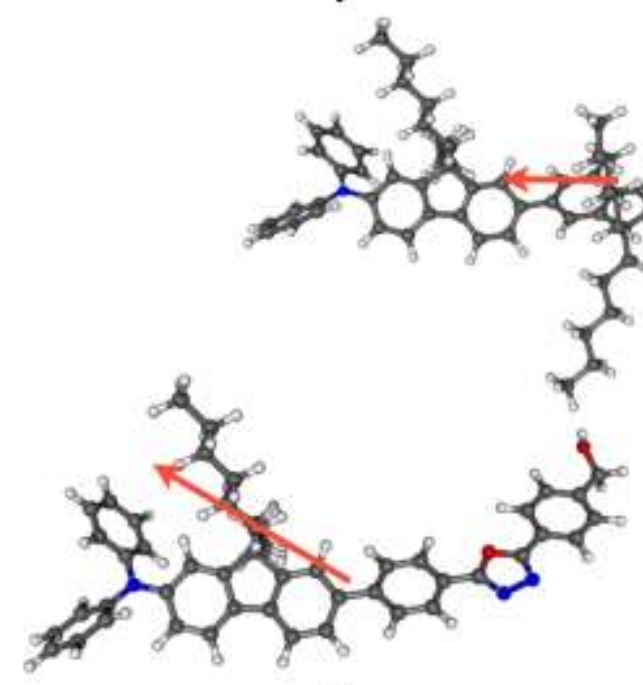

4

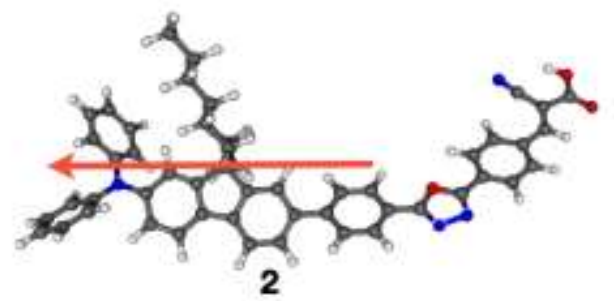

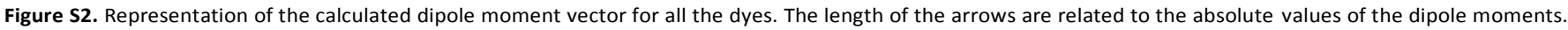
For consistency, for dye $\mathbf{3}$ diphenylamine replaces di( $p$-tolyl)amine.

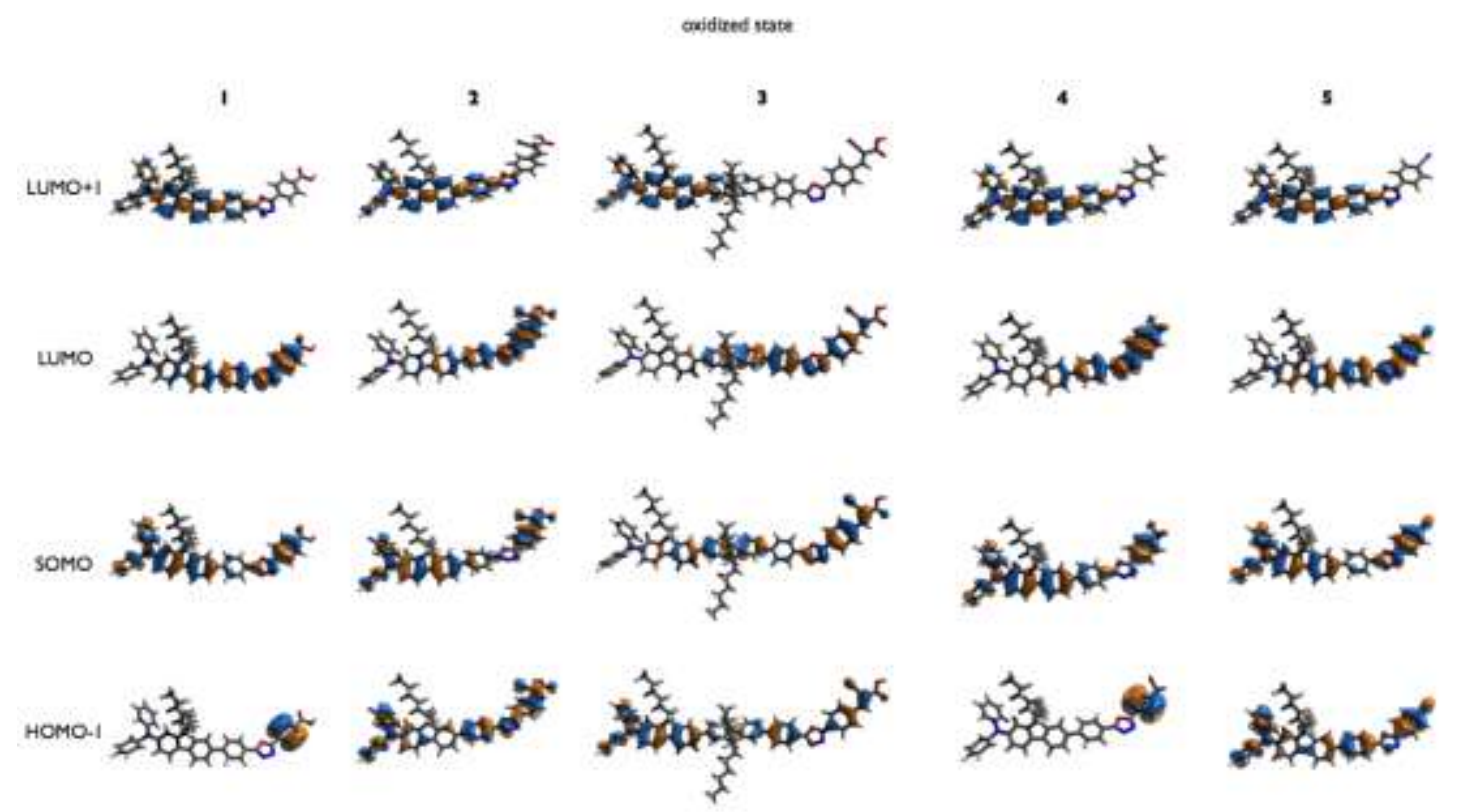

Figure S3. Representation of the frontier orbitals HOMO-1 to LUMO+1 of the positively charged oxidized state for all dyes. 


\section{Experimental Section.}

\section{Film preparation}

$5 \mu \mathrm{m}$ thick transparent films of $20 \mathrm{~nm}$ sized $\mathrm{TiO}_{2}$ particles were first screen-printed on normal flint glass slides. After annealing of the $\mathrm{TiO}_{2}$ layers at $500{ }^{\circ} \mathrm{C}$ for $30 \mathrm{~min}$, the films were cooled to $80{ }^{\circ} \mathrm{C}$ and immersed overnight into $0.1 \mathrm{mM} \mathrm{tBuOH} / \mathrm{MeCN}(1: 1 \mathrm{v} / \mathrm{v}$ mixture) solutions of the dyes. After washing the films for $30 \mathrm{~min}$ in pure solvent they were dried and were either coated with a drop of 3-methoxypropionitrile or with the Z960 electrolyte. The composition of Z960 is 1.0 M 1,3-dimethylimidazolium iodide, $0.03 \mathrm{M} \mathrm{I}_{2}, 0.05 \mathrm{M}$ lithium iodide, $0.1 \mathrm{M}$ guanidinium thiocyanate and $0.5 \mathrm{M}$ tert-butylpyridine in acetonitrile and valeronitrile solvent mixture $(85: 15 \mathrm{v} / \mathrm{v})$.

\section{Laser Studies}

Time-resolved pump-probe transient absorption measurements were performed on the previously described dye-sensitized, $5 \mu \mathrm{m}$ thick, transparent $\mathrm{TiO}_{2}$ mesoporous films in the presence and absence of the electrolyte Z960. For solution studies 1 mm quartz cuvettes have been employed.

The pump-probe technique uses a compact $1 \mathrm{kHz}$, Ti:Sapphire amplified femtosecond laser (CPA-2001, Clark-MXR), with a pulse width of about $120 \mathrm{fs}$ and a pulse energy of $1 \mathrm{~mJ}$ at a central wavelength of $775 \mathrm{~nm}$. The output beam was split into two parts for pumping a double-stage non-collinear optical parametric amplifier (NOPA) and to produce a white light continuum in a sapphire plate or $387 \mathrm{~nm}$ UV light by second harmonic generation of the CPA output in a thin BBO crystal. The NOPA was pumped by $200 \mu \mathrm{J}$ pulses at a central wavelength of $775 \mathrm{~nm}$ and the excitation wavelength was tuned to $400 \mathrm{~nm}$ to generate pulses of approximately $10 \mu \mathrm{J}$. The output pulses of the NOPA were compressed in a SF10-glass prism pair compressor down to a duration of less than $60 \mathrm{fs}$ (fwhm). Iris diaphragms were used to decrease the pulse energy down to a few $\mu \mathrm{J}$ for the pump and to $<1 \mu \mathrm{J}$ for the probe beam. Transient spectra were measured using a white light continuum (WLC) for probing.

The nanosecond laser flash photolysis employed $7 \mathrm{~ns}$ duration pulses to excite the sample at $\lambda=420 \mathrm{~nm}$ and using a $30 \mathrm{~Hz}$ repetition rate. An optical parametric oscillator (OPO-355, GWU Lasertechnik) pumped by a frequency-tripled Q-switched Nd:YAG laser (Powerlite 7030, Continuum) served as a light source. The OPO beam output was expanded by a planoconcave lens to irradiate a large cross-section of the sample, whose surface was kept at a $45^{\circ}$ angle to the excitation beam. The laser fluence on the sample was kept at a low level $\left(40 \mu \mathrm{J} \mathrm{cm}^{-2}\right.$ per pulse) to ensure that, on average, less than one electron is injected per TiO 2 nanoparticle on exposure to one laser pulse. The probe light, produced by a continuous wave xenon arc lamp, was first passed through a monochromator tuned at 750 and $900 \mathrm{~nm}$, various optical elements, the sample, and then through a second monochromator, before being detected by a fast photomultiplier tube (Hamamatsu, R9110).

\section{Device fabrication}

The device consists of two electrodes made of FTO glass (NSG 10, Nippon Sheet Glass Co, Ltd. - photoanode and TEC7, Pilkington - counterelectrode). A multilayer of $\mathrm{TiO}_{2}$ was screen printed onto the photoanode glass: on the bottom a transparent $8 \mu \mathrm{m}$-thick layer consisted of $20 \mathrm{~nm} \varnothing$ particles and on the top $5 \mu \mathrm{m}$-thick scattering layer (400 nm $\varnothing$ particles) and then sintered at $500{ }^{\circ} \mathrm{C}$. A hydrothermal $\mathrm{TiCl}_{4}$ treatment $\left(70{ }^{\circ} \mathrm{C}\right.$ for $\left.30 \mathrm{~min}\right)$ was conducted before final sintering at $450{ }^{\circ} \mathrm{C}$ for another 30 min prior to the immersion into dye solutions (dipped for $24 \mathrm{~h}$ ). The device was assembled by binding the stained photoanode and a thermally platinized counter-electrode together with a $25 \mu \mathrm{m}$-thick hot-melt polymer film (Surlyn, DuPont). The electrolyte (1 M 1,3-dimethylimidazolium iodide, $0.03 \mathrm{M} \mathrm{I}_{2}, 0.1 \mathrm{M}$ guanidinium thiocyanate, $0.5 \mathrm{M} t$-butylpyridine, $0.05 \mathrm{M}$ lithium iodide in 85:15 $\mathrm{v} / \mathrm{v}$ acetonitrile/valeronitrile) was driven into the device via a pre-drilled hole in the counter-electrode with the aid of vacuum system. The hole was sealed with the Surlyn piece and a covering glass. Metal contacts were placed on the edges of the cell.

\section{IV and IPCE measurements}

A homemade setup was used to characterize the photovoltaic performance of the devices. A $450 \mathrm{~W}$ xenon lamp (Oriel) served as a light source and the mismatch between the simulated light and real solar spectrum was corrected with a Schott K113 Tempax sunfilter (Präzisions Glas \& Optik GmbH) in the range 350-750 nm. The voltage bias was applied on the device via a Keithley 2400 digital sourcemeter (Keithley), which also recorded the generated photocurrent. The IPCE setup used for measurements consisted of a $300 \mathrm{~W}$ xenon lamp (ILC Technology), a Gemini-180 monochromator (Jobin Yvon Ltd.), a set of white diodes to apply a constant light bias, a chopper and a Lock-In Amplifier (SR830, Stanford Research Systems). The cells were masked to define the illuminated area of $0.159 \mathrm{~cm}^{2}$. 
Materials and Molecular Synthesis.

\section{General Experimental Procedures}

All air-sensitive reactions were conducted under a blanket of argon which was dried by passage through a column of phosphorus pentoxide. All commercial chemicals were used without further purification unless otherwise stated. Anhydrous toluene, tetrahydrofuran (THF) and diethyl ether $\left(\mathrm{Et}_{2} \mathrm{O}\right)$ were dried through an HPLC column on an Innovative Technology Inc. solvent purification system. Anhydrous pyridine was dried over $\mathrm{KOH}$ pellets. Column chromatography was carried out using $40-60 \mu \mathrm{m}$ mesh silica. Analytical thin layer chromatography was performed on $20 \mathrm{~mm}$ pre-coated plates of silica gel (Merck, silica gel $\left.60 \mathrm{~F}_{254}\right)$, visualization was made using ultraviolet light $(254 \mathrm{~nm})$. NMR spectra were recorded on: Bruker Avance-400 $\left({ }^{1} \mathrm{H}\right.$ NMR: $400 \mathrm{MHz},{ }^{13} \mathrm{C}$ NMR: $\left.101 \mathrm{MHz}\right)$, Varian Mercury-200 $\left({ }^{1} \mathrm{H}\right.$ NMR: $\left.200 \mathrm{MHz}\right)$, Varian Mercury-400 $\left({ }^{1} \mathrm{H}\right.$ NMR: $400 \mathrm{MHz},{ }^{13} \mathrm{C}$ NMR: $126 \mathrm{MHz})$, Varian Inova-500 ( ${ }^{1} \mathrm{H}$ NMR: $\left.500 \mathrm{MHz},{ }^{13} \mathrm{C} \mathrm{NMR} 126 \mathrm{MHz}\right)$ and Varian VNMRS-700 $\left({ }^{1} \mathrm{H} \mathrm{NMR}\right.$ : $700 \mathrm{MHz},{ }^{13} \mathrm{C}$ NMR $176 \mathrm{MHz}$ ) spectrometers. Melting points were determined in open-ended capillaries using a Stuart Scientific SMP3 melting point apparatus at a ramping rate of $5^{\circ} \mathrm{C} / \mathrm{min}$. Mass spectra were measured on a Waters Xevo OTofMS with an ASAP probe. Electron ionisation (EI) mass spectra were recorded on a Thermoquest Trace or a Thermo-Finnigan DSQ.

\section{General Miyaura Borylation Procedure}

In a flame-dried flask under an atmosphere of argon the aryl halide (1.0 equiv.) was dissolved in DMF ( $2 \mathrm{~mL}$ per mmol of halide) and degassed with argon for $20 \mathrm{~min}$. To this stirred solution $\mathrm{B}_{2} \mathrm{pin}_{2}$ (1.4 equiv.) and potassium acetate (1.6 equiv.) were added and the mixture degassed for a further $10 \mathrm{~min}$, after which time $\left[\mathrm{PdCl}_{2}(\mathrm{dppf})\right](2 \mathrm{~mol} \%)$ was added and the reaction mixture was heated to $80{ }^{\circ} \mathrm{C}$ for $15 \mathrm{~h}$. The mixture was then cooled, water added and extracted with diethyl ether. The organic extracts are combined and the solvent removed under reduced pressure. The product was purified by column chromatography on silic a gel.

\section{General Suzuki-Miyaura Cross-Coupling Procedure}

In a flame-dried flask under an atmosphere of argon the relevant aryl halide and boronic ester or acid were dissolved in anhydrous THF ( $2 \mathrm{~mL}$ per mmol of halide) and degassed for $20 \mathrm{~min}$. To this stirred solution aqueous $\mathrm{NaOH}(2-2.5$ equiv.) was added and the mixture degassed for a further $10 \mathrm{~min}$. After this time $\left[\mathrm{PdCl}_{2}\left(\mathrm{PPh}_{3}\right)_{2}\right](2 \mathrm{~mol} \%)$ was added and the reaction mixture heated to $65{ }^{\circ} \mathrm{C}$ for $15 \mathrm{~h}$ under argon. The reaction mixture was then allowed to cool, filtered through a plug of Celite, washed with water and extracted with diethyl ether. The solvent was removed from the combined organic extracts under reduced pressure and the crude product purified by column chromatography on silica gel.

\section{4-(5-(4-Bromophenyl)-1,3,4-oxadiazol-2-yl)benzonitrile (C)}

To a stirred solution of 4-cyanobenzoic acid (A) $(2.00 \mathrm{~g}, 0.014 \mathrm{~mol})$, 4-bromobenzohydrazide $(\mathbf{B})(2.90 \mathrm{~g}, 0.014 \mathrm{~mol})$ and TBTU $(4.50 \mathrm{~g}, 0.014 \mathrm{~mol})$ DIPEA $(2.44 \mathrm{~mL}, 0.014 \mathrm{~mol})$ were added. The reaction mixture was stirred at room temperature for $24 \mathrm{~h}$. After this time it was poured onto water and extracted with ethyl acetate. The combined organic extracts were washed sequentially with saturated $\mathrm{NaHCO}_{3}$ solution and then $1 \mathrm{M} \mathrm{NaHSO}_{4}$ solution. The solvent was removed from the organic layers under reduced pressure. The crude 4-bromo- $N$ '-(4-cyanobenzoyl)benzohydrazide was dissolved in $\mathrm{POCl}_{3}(5 \mathrm{~mL})$ and heated to reflux for $12 \mathrm{~h}$. The excess $\mathrm{POCl}_{3}$ was then removed by distillation and the crude product purified by column chromatography on silica gel using chloroform as eluent to yield $\mathbf{C}$ as a white solid $(0.71 \mathrm{~g}, 16 \%)$ Mp: $220.3-221.8{ }^{\circ} \mathrm{C} .{ }^{1} \mathrm{H} \mathrm{NMR}\left(400 \mathrm{MHz}, \mathrm{CDCl}_{3}\right): \delta 8.20(\mathrm{~d}, J=8.5$ $\left.\mathrm{Hz}, 2 \mathrm{H}), 7.95(\mathrm{~d}, J=9.0 \mathrm{~Hz}, 2 \mathrm{H}), 7.84-7.75(\mathrm{~d}, 8.5 \mathrm{~Hz}, 2 \mathrm{H}), 7.64(\mathrm{~d}, J=9.0 \mathrm{~Hz}, 2 \mathrm{H}) ;{ }^{13} \mathrm{C} \mathrm{NMR}(101 \mathrm{MHz}, \mathrm{CDCl})_{3}\right): \delta 164.68$, $163.21,132.92,132.62,128.47,127.59,127.38,127.09,122.28,117.82,115.38 ;\left(\mathrm{HRMS} \mathrm{ASAP}^{+}\right) \mathrm{calcd}$ for $\mathrm{C}_{18} \mathrm{H}_{8}{ }^{79} \mathrm{BrN}_{3} \mathrm{O}$ : 324.9851, Found: 324.9851.

\section{4-(5-(4-(4,4,5,5-Tetramethyl-1,3,2-dioxaborolan-2-yl)phenyl)-1,3,4-oxadiazol-2-yl)benzonitrile (D)}

The standard Miyaura borylation procedure was followed using the following reagents: $\mathbf{C}(0.30 \mathrm{~g}, 0.92 \mathrm{mmol}), \mathrm{B}_{2} \mathrm{pin} \mathrm{p}_{2}(0.30 \mathrm{~g}$, $1.20 \mathrm{mmol}),\left[\mathrm{PdCl}_{2}\right.$ (dppf)] (20 mg, $\left.0.03 \mathrm{mmol}\right), \mathrm{KOAc}(0.23 \mathrm{~g}, 2.3 \mathrm{mmol})$ and DMF (10 mL). The product was purified by column chromatography on silica gel using $1: 1(\mathrm{v} / \mathrm{v})$ petroleum ether : DCM as eluent to yield D as a white solid (0.18 g, $51 \%)$. Mp: $241.9-243.8^{\circ} \mathrm{C} .{ }^{1} \mathrm{H}$ NMR $\left(400 \mathrm{MHz} \mathrm{CDCl}_{3}\right): \delta 8.28(\mathrm{~d}, J=8.5 \mathrm{~Hz}, 2 \mathrm{H}), 8.13(\mathrm{~d}, J=8.5 \mathrm{~Hz}, 2 \mathrm{H}), 7.97(\mathrm{~d}, J=8.5 \mathrm{~Hz}, 2 \mathrm{H})$, $7.84(\mathrm{~d}, J=8.5 \mathrm{~Hz}, 2 \mathrm{H}), 1.38(\mathrm{~s}, 12 \mathrm{H}) ;{ }^{13} \mathrm{C}$ NMR $\left(101 \mathrm{MHz}, \mathrm{CDCl}_{3}\right): \delta 165.40,163.15,135.42,132.87,127.77,127.40,126.12$, 125.46, 117.88, 115.23, 84.32, 25.02, 24.90. HRMS (ASAP ), calcd for $\mathrm{C}_{21} \mathrm{H}_{21}{ }^{10} \mathrm{BN}_{3} \mathrm{O}_{2}: 374.1753$, Found: 374.1791 .

\section{4-(5-(4-(7-(Diphenylamino)-9,9-dihexyl-9H-fluoren-2-yl)phenyl)-1,3,4-oxadiazol-2-yl)benzonitrile (5)}

The general Suzuki-Miyaura cross-coupling procedure was followed using the following reagents: $\mathbf{D}(0.28 \mathrm{~g}, 0.75 \mathrm{mmol}), \mathbf{E}^{1}(0.48$ $\mathrm{g}, 0.83 \mathrm{mmol}),\left[\mathrm{PdCl}_{2}\left(\mathrm{PPh}_{3}\right)_{2}\right](25 \mathrm{mg}, 0.04 \mathrm{mmol}), \mathrm{NaOH}\left(0.08 \mathrm{~g}\right.$ in $\left.5 \mathrm{~mL} \mathrm{H}_{2} \mathrm{O}\right)$ and THF (10 mL). The product was purified by column chromatography on silica gel using initially $7: 3(\mathrm{v} / \mathrm{v})$ petroleum ether : diethyl ether changing to $1: 1(\mathrm{v} / \mathrm{v})$ petroleum ether : diethyl ether as eluent to yield 5 as a yellow solid $(0.25 \mathrm{~g}, 45 \%) . \mathrm{Mp} 167.9-168.7{ }^{\circ} \mathrm{C} .{ }^{1} \mathrm{H} \mathrm{NMR}(600 \mathrm{MHz}, \mathrm{CDCl}): \delta 8.29$ $(\mathrm{d}, J=8.0 \mathrm{~Hz}, 2 \mathrm{H}), 8.22(\mathrm{~d}, J=8.0 \mathrm{~Hz}, 2 \mathrm{H}), 7.84(\mathrm{t}, J=7.5 \mathrm{~Hz}, 4 \mathrm{H}), 7.69(\mathrm{~d}, J=7.5 \mathrm{~Hz}, 1 \mathrm{H}), 7.64-7.52(\mathrm{~m}, 3 \mathrm{H}), 7.29-7.20$ $(\mathrm{m}, 4 \mathrm{H}), 7.13(\mathrm{~d}, J=7.0 \mathrm{~Hz}, 5 \mathrm{H}), 7.02(\mathrm{~m}, 3 \mathrm{H}), 2.00-1.80(\mathrm{~m}, 4 \mathrm{H}), 1.19-0.94(\mathrm{~m}, 12 \mathrm{H}), 0.78(\mathrm{t}, J=7.0 \mathrm{~Hz}, 6 \mathrm{H}), 0.76-0.59$ $(\mathrm{m}, 4 \mathrm{H}) ;{ }^{13} \mathrm{C}$ NMR $\left(151 \mathrm{MHz}, \mathrm{CDCl}_{3}\right): \delta 165.38,162.98,152.46,151.60,147.89,147.54,145.54,141.42,137.44,135.38,132.87$, $129.17,127.85,127.69,127.52,127.33,126.12,123.91,123.43,122.61,121.64,121.17,120.63,119.53,119.14,117.90,115.12$, 55.22, 40.22, 31.48, 29.59, 23.78, 22.52, 14.01; HRMS (ASAP $)$, calcd for $\mathrm{C}_{52} \mathrm{H}_{50} \mathrm{~N}_{4} \mathrm{O}$ : 746.3985, found: 746.3962 .

\section{4-(5-(4-(7-(Diphenylamino)-9,9-dihexyl-9H-fluoren-2-yl)phenyl)-1,3,4-oxadiazol-2-yl)benzoic acid (1)}

A mixture of $5(0.065 \mathrm{mg}, 0.09 \mathrm{mmol})$ and potassium hydroxide $(0.13 \mathrm{~g}, 2.3 \mathrm{mmol})$ in $3: 1$ ethanol : water solution (10 mL) was heated to reflux for $15 \mathrm{~h}$. After this time, when the solid had dissolved, the $\mathrm{pH}$ was altered to $\mathrm{pH} 3 \mathrm{by}$ addition of dilute 
hydrochloric acid. The resulting precipitate was filtered, dissolved in dichloromethane and washed with $\mathrm{NaHCO}_{3}$ solution. The organic extracts were combined and the solvent removed under reduced pressure. The product was purified by column chromatography on silica gel using dichloromethane and then with dichloromethane and 5\% acetic acid as eluent to yield $\mathbf{1}$ as a yellow solid (38 mg, 57\%). Mp: $129.7-132.1{ }^{\circ} \mathrm{C} .{ }^{1} \mathrm{H}$ NMR $\left.(600 \mathrm{MHz} \text {, acetone-d })_{6}\right): \delta .16(\mathrm{~d}, J=8.0 \mathrm{~Hz}, 2 \mathrm{H}), 8.10(\mathrm{~d}, J=7.0 \mathrm{~Hz}$, $4 \mathrm{H}), 7.89(\mathrm{~d}, J=8.0 \mathrm{~Hz}, 2 \mathrm{H}), 7.83(\mathrm{~d}, J=7.5 \mathrm{~Hz}, 2 \mathrm{H}), 7.76(\mathrm{~d}, J=8.0 \mathrm{~Hz}, 1 \mathrm{H}), 7.73(\mathrm{~d}, J=8.0 \mathrm{~Hz}, 1 \mathrm{H}), 7.32-7.26(\mathrm{~m}, 4 \mathrm{H}), 7.20$ $(\mathrm{d}, J=2.0 \mathrm{~Hz}, 1 \mathrm{H}), 7.13-7.07(\mathrm{~m}, 4 \mathrm{H}), 7.07-7.00(\mathrm{~m}, 3 \mathrm{H}), 2.18-1.88(\mathrm{~m}, 4 \mathrm{H}), 1.18-1.04(\mathrm{~m}, 12 \mathrm{H}), 0.77(\mathrm{t}, J=7.0 \mathrm{~Hz}, 6 \mathrm{H})$, $0.72(\mathrm{~s}, 4 \mathrm{H}) ;{ }^{13} \mathrm{C}$ NMR $\left(151 \mathrm{MHz}\right.$, acetone-d $\left.\mathrm{d}_{6}\right): \delta 170.96,166.02,165.71,165.43,152.46,151.49,148.00,147.54,144.73,141.13$, $137.96,136.85,135.92,133.55,131.24,129.68,129.25,128.09,127.61,126.82,126.12,123.71,123.50,122.70,121.33,120.81$, 119.65, 119.30, 55.18, 39.86, 31.30, 23.70, 22.23, 19.51, 13.34; HRMS (ASAP ${ }^{+}$, calc for $\mathrm{C}_{52} \mathrm{H}_{52} \mathrm{~N}_{3} \mathrm{O}_{3}$ : 766.4009. Found: 766.4023.

\section{2-(4-Bromophenyl)-5-p-tolyl-1,3,4-oxadiazole (H)}

To a stirred solution of 5-p-tolyl- $1 H$-tetrazole $(\mathbf{F})(5.45 \mathrm{~g}, 33.0 \mathrm{mmol})$ in pyridine $(50 \mathrm{~mL}) 4$-bromobenzoyl chloride $(\mathbf{G})(7.84 \mathrm{~g}$, $36.0 \mathrm{mmol}$ ) was added and the mixture was heated to reflux for $72 \mathrm{~h}$. The reaction mixture was cooled and poured onto water to precipitate $\mathbf{H}$ which was filtered, dried and isolated as a white solid (6.12 g, 57\%). Mp: $205.0-206.2{ }^{\circ} \mathrm{C}$. ${ }^{1} \mathrm{H} \mathrm{NMR}(400 \mathrm{MHz}$, $\left.\mathrm{CDCl}_{3}\right): \delta 8.05-7.92(\mathrm{~m}, 4 \mathrm{H}), 7.68(\mathrm{~m}, 2 \mathrm{H}), 7.36-7.31(\mathrm{~m}, 2 \mathrm{H}), 2.45(\mathrm{~s}, 3 \mathrm{H}) ;{ }^{13} \mathrm{C} \mathrm{NMR}\left(101 \mathrm{MHz}^{\mathrm{CDCl}} \mathrm{CD}_{3}\right): \delta 164.93,163.64$, $142.50,132.41,129.83,128.28,126.94,126.29,122.96,120.96,21.68$. MS (ASAP+) 314 (85\%, M+), 179 (100), 119 (45); HRMS $\left(\mathrm{ASAP}^{+}\right.$) calcd for $\mathrm{C}_{15} \mathrm{H}_{12} \mathrm{~N}_{2} \mathrm{OBr}$ : 315.0133. Found: 315.0150 .

\section{2-(4-(Bromomethyl)phenyl)-5-(4-bromophenyl)-1,3,4-oxadiazole (I)}

To a solution of $\mathbf{H}(2.00 \mathrm{~g}, 6.3 \mathrm{mmol})$ in 1,2-dichloroethane $(50 \mathrm{~mL}) \mathrm{N}$-bromosuccinimide $(1.07 \mathrm{~g}, 6.0 \mathrm{mmol})$ and benzoyl peroxide $(0.30 \mathrm{~g}, 1.2 \mathrm{mmol})$ were added. The reaction mixture was heated to $70{ }^{\circ} \mathrm{C}$ for $15 \mathrm{~h}$, then cooled and the solvent removed under reduced pressure. The product was purified by column chromatography using initially petroleum ether and then petroleum ether : ethyl acetate $(1: 1 \mathrm{v} / \mathrm{v})$ as eluents. The product was further purified by recrystallization from acetonitrile and $\mathbf{I}$ was isolated as a white solid $(1.12 \mathrm{~g}, 48 \%)$. Mp $184.2-186.7{ }^{\circ} \mathrm{C} .{ }^{1} \mathrm{H} \mathrm{NMR}\left(400 \mathrm{MHz}, \mathrm{CDCl}_{3}\right): \delta 8.12(\mathrm{~d}, J=8.5 \mathrm{~Hz}, 2 \mathrm{H}), 8.01(\mathrm{~d}, J=9.0 \mathrm{~Hz}$, $2 \mathrm{H}), 7.69(\mathrm{~d}, J=9.0 \mathrm{~Hz}, 2 \mathrm{H}), 7.57(\mathrm{~d}, J=8.5 \mathrm{~Hz}, 2 \mathrm{H}), 4.54(\mathrm{~s}, 2 \mathrm{H}) ;{ }^{13} \mathrm{C} \mathrm{NMR}\left(176 \mathrm{MHz}, \mathrm{CDCl}_{3}\right): \delta 164.25,163.98,141.62$, 132.45, 129.77, 128.32, 127.37, 126.53, 123.60, 122.71, 32.15; HRMS (ASAP ${ }^{+}$), for $\mathrm{C}_{15} \mathrm{H}_{10} \mathrm{Br}_{2} \mathrm{~N}_{2} \mathrm{O}$ calcd: 391.9160 . Found: 391.9171.

\section{4-(5-(4-(4,4,5,5-Tetramethyl-1,3,2-dioxaborolan-2-yl)phenyl)-1,3,4-oxadiazol-2-yl)benzyl acetate (J)}

The general Miyaura borylation procedure was followed using the following reagents: $\mathbf{I}(0.50 \mathrm{~g}, 1.6 \mathrm{mmol}), \mathrm{B}_{2} \mathrm{Pin} \mathrm{m}_{2}(1.02 \mathrm{~g}, 4$ $\mathrm{mmol})$, potassium acetate $(0.31 \mathrm{~g}, 3.2 \mathrm{mmol})$ and $\left[\mathrm{PdCl}_{2}(\mathrm{dppf})\right](35 \mathrm{mg}, 0.5 \mathrm{mmol})$. The product was purified by column chromatography on silica gel using petroleum ether (b.p. $40-60{ }^{\circ} \mathrm{C}$ ) with $10 \%$ then $30 \%$ ethyl acetate as eluent to yield $\mathbf{J}$ as a white solid (0.26 g, 48\%). Mp: $168.1-169.4{ }^{\circ} \mathrm{C} .{ }^{1} \mathrm{H}$ NMR $\left(400 \mathrm{MHz}, \mathrm{CDCl}_{3}\right): \delta 8.14(\mathrm{~m}, 4 \mathrm{H}), 7.97(\mathrm{~d}, J=8.5 \mathrm{~Hz}, 2 \mathrm{H}), 7.52(\mathrm{~d}, J$ $=8.5 \mathrm{~Hz}, 2 \mathrm{H}), 5.19(\mathrm{~s}, 2 \mathrm{H}), 2,11(\mathrm{~s}, 3 \mathrm{H}), 1.38(\mathrm{~s}, 12 \mathrm{H}) ;{ }^{13} \mathrm{C} \mathrm{NMR}\left(101 \mathrm{MHz}, \mathrm{CDCl}_{3}\right): \delta 170.63,164.70,164.37,139.86,135.32$, 128.53, 127.20, 125.98, 123.70, 84.24, 65.49, 24.89, 20.89; HRMS (ASAP ${ }^{+}$), for $\mathrm{C}_{23} \mathrm{H}_{25} \mathrm{~N}_{2} \mathrm{O}_{5}{ }^{10} \mathrm{~B}$ calcd: 420.1971, found: 420.1964 .

(4-(5-(4-(7-(Diphenylamino)-9,9-dihexyl-9H-fluoren-2-yl)phenyl)-1,3,4-oxadiazol-2-yl)phenyl)methanol (4)

The general Suzuki-Miyaura procedure was followed using the following reagents: J $(0.10 \mathrm{~g}, 0.24 \mathrm{mmol}), \mathbf{E}(0.14 \mathrm{~g}, 0.25 \mathrm{mmol})$, sodium hydroxide $(0.02 \mathrm{~g}, 0.57 \mathrm{mmol}), \mathrm{H}_{2} \mathrm{O}(5 \mathrm{~mL})$ and $\left[\mathrm{PdCl}_{2}\left(\mathrm{PPh}_{3}\right)_{2}\right](0.01 \mathrm{~g}, 0.01 \mathrm{mmol})$. The product was purified by column chromatography on silica gel using $1: 1(\mathrm{v} / \mathrm{v})$ petroleum ether (b.p. $\left.40-60{ }^{\circ} \mathrm{C}\right)$ : diethyl ether as eluent. The product 4 was isolated as a yellow solid $(0.14 \mathrm{~g}, 76 \%)$. Mp: $73.9-76.6{ }^{\circ} \mathrm{C} .{ }^{1} \mathrm{H}$ NMR $\left(600 \mathrm{MHz}, \mathrm{CDCl}_{3}\right): \delta 8.23(\mathrm{~d}, J=8.5 \mathrm{~Hz}, 2 \mathrm{H}), 8.17(\mathrm{~d}, J=$ $8.5 \mathrm{~Hz}, 2 \mathrm{H}), 7.83(\mathrm{~d}, J=8.5 \mathrm{~Hz}, 2 \mathrm{H}), 7.70(\mathrm{~d}, J=8.0 \mathrm{~Hz}, 1 \mathrm{H}), 7.62(\mathrm{dd}, J=8.0,1.7 \mathrm{~Hz}, 1 \mathrm{H}), 7.60(\mathrm{~d}, J=8.0 \mathrm{~Hz}, 1 \mathrm{H}), 7.58-7.54$ $(\mathrm{m}, 3 \mathrm{H}), 7.28-7.23(\mathrm{~m}, 4 \mathrm{H}), 7.16-7.11(\mathrm{~m}, 5 \mathrm{H}), 7.06-6.99(\mathrm{~m}, 3 \mathrm{H}), 4.83(\mathrm{~s}, 2 \mathrm{H}), 1.99-1.80(\mathrm{~m}, 4 \mathrm{H}), 1.19-1.00(\mathrm{~m}, 12 \mathrm{H})$, $0.79(\mathrm{t}, J=7.0 \mathrm{~Hz}, 6 \mathrm{H}), 0.77-0.65(\mathrm{~m}, 4 \mathrm{H})(\mathrm{OH}$ not observed $) ;{ }^{13} \mathrm{C}$ NMR $\left(151 \mathrm{MHz}, \mathrm{CDCl}_{3}\right): \delta 164.55,164.39,152.45,151.55$, $147.91,147.45,145.00,144.70,141.24,137.67,135.49,129.15,127.58,127.34,127.24,127.15,126.08,123.87,123.45,123.14$, $122.56,122.23,121.18,120.59,119.49,119.20,64.70,55.21,53.38,40.22,31.47,30.89,29.58,24.83,23.78,22.52,14.00$; HRMS (ASAP ${ }^{+}$), calcd for $\mathrm{C}_{52} \mathrm{H}_{53} \mathrm{~N}_{3} \mathrm{O}_{2}: 751.4138$, found: 751.4161 .

\section{4-(5-(4-(7-(Diphenylamino)-9,9-dihexyl-9H-fluoren-2-yl)phenyl)-1,3,4-oxadiazol-2-yl)benzaldehyde (K)}

To a solution of $4(0.15 \mathrm{~g}, 0.20 \mathrm{mmol})$ in dichloromethane $(5 \mathrm{~mL})$ pyridinium chlorochromate $(51 \mathrm{mg}, 0.24 \mathrm{mmol})$ in dichloromethane $(5 \mathrm{~mL})$ was added dropwise. The resulting mixture was stirred at room temperature for $1 \mathrm{~h}$. After this time the reaction mixture was filtered through a Celite plug. The product was then purified by column chromatography on silica gel using 1 : $1(\mathrm{v} / \mathrm{v})$ petroleum ether : diethyl ether as eluent to yield $\mathbf{K}$ as a yellow solid $(89 \mathrm{mg}, 60 \%) . \mathrm{Mp}: 148.3-149.9{ }^{\circ} \mathrm{C}$. ${ }^{1} \mathrm{H}$ NMR $(500$ $\left.\mathrm{MHz}, \mathrm{CDCl}_{3}\right): \delta 10.08(\mathrm{~s}, 1 \mathrm{H}), 8.31(\mathrm{~d}, J=8.0 \mathrm{~Hz}, 2 \mathrm{H}), 8.20(\mathrm{~d}, J=8.5 \mathrm{~Hz}, 2 \mathrm{H}), 8.03(\mathrm{~d}, J=8.5 \mathrm{~Hz}, 2 \mathrm{H}), 7.80(\mathrm{~d}, J=8.5 \mathrm{~Hz}$, $2 \mathrm{H}), 7.66(\mathrm{~d}, J=8.0 \mathrm{~Hz}, 1 \mathrm{H}), 7.60-7.51(\mathrm{~m}, 3 \mathrm{H}), 7.26-7.18(\mathrm{~m}, 4 \mathrm{H}), 7.12-7.05(\mathrm{~m}, 5 \mathrm{H}), 7.04-6.94(\mathrm{~m}, 3 \mathrm{H}), 1.97-1.76(\mathrm{~m}$, $4 \mathrm{H}), 1.15-0.96(\mathrm{~m}, 12 \mathrm{H}), 0.75(\mathrm{t}, J=7.0 \mathrm{~Hz}, 6 \mathrm{H}), 0.72-0.62(\mathrm{~m}, 4 \mathrm{H}) ;{ }^{13} \mathrm{C} \mathrm{NMR}\left(126 \mathrm{MHz}, \mathrm{CDCl}_{3}\right): \delta 191.46,165.53,163.81$, $152.72,151.85,148.16,147.77,145.66,141.63,138.42,137.77,135.68,130.51,129.43,129.23,127.93,127.77,127.70,126.38$, 124.16, 123.70, 122.86, 122.07, 121.44, 120.89, 119.79, 119.42, 55.48, 40.49, 31.74, 29.85, 24.05, 22.79, 14.28; HRMS (ASAP $)^{+}$, calc for $\mathrm{C}_{52} \mathrm{H}_{51} \mathrm{~N}_{3} \mathrm{O}_{2}$ : 749.3981, Found: 749.3961 .

2-Cyano-3-(4-(5-(4-(7-(diphenylamino)-9,9-dihexyl-9H-fluoren-2-yl)phenyl)-1,3,4-oxadiazol-2-yl)phenyl)acrylic acid (2) 
To a solution of $\mathbf{K}$ (46 mg, $0.061 \mathrm{mmol})$ and ammonium acetate ( $1 \mathrm{mg}, 0.012 \mathrm{mmol})$ in acetic acid ( $2 \mathrm{~mL})$ was added cyanoacetic acid $(15 \mathrm{mg}, 0.18 \mathrm{mmol})$. This stirred mixture was heated to reflux for $15 \mathrm{~h}$ after which time it was cooled, poured onto water and filtered. The solid was dissolved in dichloromethane and washed with water. The solvent was removed from the combined organic extracts and the crude product was purified by column chromatography using initially dichloromethane, then dichloromethane:methanol $(4: 1 \mathrm{v} / \mathrm{v})$ as eluent to yield 2 as a yellow solid $(25 \mathrm{mg}, 50 \%)$. Mp: $119.3-120.0{ }^{\circ} \mathrm{C} .{ }^{1} \mathrm{H}$ NMR $(400$ $\left.\mathrm{MHz}, \mathrm{CD}_{3} \mathrm{OD} / \mathrm{CS}_{2}\right): \delta 8.27(\mathrm{~m}, 4 \mathrm{H}), 8.20-8.12(\mathrm{~m}, 3 \mathrm{H}), 7.96-7.87(\mathrm{~m}, 2 \mathrm{H}), 7.74(\mathrm{~d}, J=8.5 \mathrm{~Hz}, 1 \mathrm{H}), 7.70-7.59(\mathrm{~m}, 3 \mathrm{H}), 7.31$ $-7.19(\mathrm{~m}, 4 \mathrm{H}), 7.16-7.07(\mathrm{~m}, 5 \mathrm{H}), 7.03(\mathrm{~m}, 3 \mathrm{H}), 2.12-1.85(\mathrm{~m}, 4 \mathrm{H}), 1.25-1.00(\mathrm{~m}, 12 \mathrm{H}), 0.87-0.78(\mathrm{~m}, 6 \mathrm{H}), 0.73(\mathrm{~s}, 4 \mathrm{H})$; ${ }^{13} \mathrm{C}$ NMR $\left(126 \mathrm{MHz}, \mathrm{CDCl}_{3}\right): \delta 177.62,152.67,151.68,150.91,148.14,147.60,141.31,135.68,129.37,127.55,126.38,124.11$, $122.78,120.87,119.77,119.40,55.42,40.40,31.63,29.93,29.75,24.03,22.68,14.22 ; \mathrm{HRMS}_{(}\left(\mathrm{ES}^{+}\right)$, calc for $\mathrm{C}_{55} \mathrm{H}_{52} \mathrm{~N}_{4} \mathrm{O}_{3}$ : 816.4039, Found: 816.4042; IR (THF solution) $\mathrm{cm}^{-1}$; $3372(\mathrm{O}-\mathrm{H}), 3502(\mathrm{O}-\mathrm{H}), 2217(\mathrm{C} \equiv \mathrm{N}), 1641(\mathrm{C}=\mathrm{O}), 1596(\mathrm{C}=\mathrm{N})$.

\section{(4-(5-(4-(7'-(di-p-tolylamino)-9,9,9',9'-tetrahexyl-9H,9' H-[2,2'-bifluoren]-7-yl)phenyl)-1,3,4-oxadiazol-2-yl)benzaldehyde}

(L)

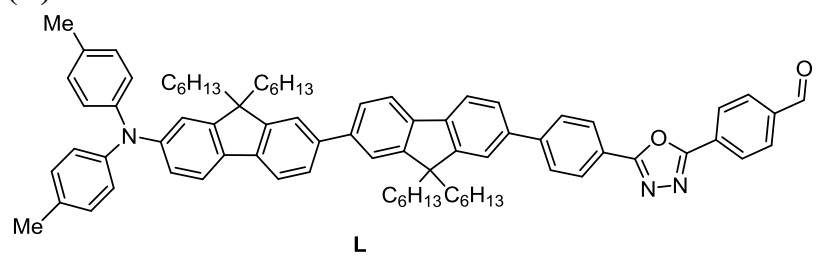

Following literature precedents, ${ }^{2}$ compound $\mathbf{L}$ was obtained as a yellow solid in $68 \%$ yield. Mp: $150.2-151.8{ }^{\circ} \mathrm{C}$. ${ }^{1} \mathrm{H}$ NMR $(500$ $\mathrm{MHz}_{\mathrm{CDCl}}$ ): $\delta 10.04(\mathrm{~s}, 1 \mathrm{H}), 8.22(\mathrm{dd}, J=26.3,8.2 \mathrm{~Hz}, 5 \mathrm{H}), 8.08-7.93(\mathrm{~m}, 4 \mathrm{H}), 7.70-7.61(\mathrm{~m}, 2 \mathrm{H}), 7.60-7.50(\mathrm{~m}, 7 \mathrm{H}), 7.43$ $(\mathrm{m}, 2 \mathrm{H}), 7.00-6.86(\mathrm{~m}, 8 \mathrm{H}), 2.22-1.90(\mathrm{~m}, 14 \mathrm{H}), 1.10-0.56(\mathrm{~m}, 44 \mathrm{H}) ;{ }^{13} \mathrm{C} \mathrm{NMR}\left(126 \mathrm{MHz}, \mathrm{CDCl}_{3}\right): \delta 191.26,157.91,156.73$, $155.80,155.72,154.33,151.99,150.82,149.55,148.43,148.40,145.00,144.02,143.61,142.30,142.01,141.10,141.04,141.00$, $138.70,137.55,134.90,134.13,132.75,131.94,130.89,130.39,129.44,129.21,127.67,126.55,125.22,125.19,124.50,124.20$, $124.10,123.66,122.32,122.01,121.20,60.00,59.23,44.21,43.10,42.01,35.01,34.88,32.88,32.51,28.01,25.90,24.99,23.54$, 16.11; HRMS (ASAP ${ }^{+}$), calc for $\mathrm{C}_{79} \mathrm{H}_{87} \mathrm{~N}_{3} \mathrm{O}_{2}: 1109.6798$, Found: 1109.6796 .

\section{2-Cyano-3-(4-(5-(4-(7'-(di-p-tolylamino)-9,9,9',9'-tetrahexyl-9H,9' H-[2,2'-bifluoren]-7-yl)phenyl)-1,3,4-oxadiazol-2- yl)phenyl)acrylic acid (3)}

To a solution of the aldehyde precursor $\mathbf{L}(50 \mathrm{mg}, 0.045 \mathrm{mmol})$ and ammonium acetate $(0.7 \mathrm{mg}, 0.01 \mathrm{mmol})$ in acetic acid (2 mL) was added cyanoacetic acid $(11.5 \mathrm{mg}, 0.135 \mathrm{mmol})$. The mixture was refluxed under argon for $15 \mathrm{~h}$ then poured onto water and filtered. The crude solid was dissolved in dichloromethane $(20 \mathrm{~mL})$ and washed with water $(2 \times 50 \mathrm{~mL})$. The solvent was removed from the combined organic extracts and the crude product was purified by column chromatography using first dichloromethane then dichloromethane/methanol $(4: 1 \mathrm{v} / \mathrm{v})$ mixture as eluent to yield $\mathbf{3}$ as a yellow solid $(38 \mathrm{mg}, 71 \%)$. $\mathrm{Mp}: 108.2-109.8{ }^{\circ} \mathrm{C}$. ${ }^{1} \mathrm{H}$ NMR (600 MHz, $\left.\mathrm{CDCl}_{3} / \mathrm{CD}_{3} \mathrm{OD}\right): \delta 8.19(\mathrm{dd}, J=26.3,8.2 \mathrm{~Hz}, 5 \mathrm{H}), 8.08(\mathrm{~s}, 2 \mathrm{H}), 7.81(\mathrm{~d}, J=8.2 \mathrm{~Hz}, 2 \mathrm{H}), 7.78-7.71(\mathrm{~m}, 2 \mathrm{H})$, $7.65-7.54(\mathrm{~m}, 7 \mathrm{H}), 7.49(\mathrm{dd}, J=8.8,4.8 \mathrm{~Hz}, 2 \mathrm{H}), 7.06-6.92(\mathrm{~m}, 9 \mathrm{H}), 2.12-1.75(\mathrm{~m}, 14 \mathrm{H}), 1.15-0.57(\mathrm{~m}, 44 \mathrm{H}) .{ }^{13} \mathrm{C} \mathrm{NMR}$ (101 MHz, $\left.\mathrm{CDCl}_{3} / \mathrm{CD}_{3} \mathrm{OD}\right): \delta 168.15,166.72,156.93,155.33,154.88,154.72,154.27,151.64,150.52,149.31,148.54,148.48$, $144.22,143.96,143.35,142.32,141.12,141.02,140.98,138.22,138.18,137.98,134.94,134.01,132.65,130.74,130.44,130.30$, $129.11,129.03,126.93,126.68,125.34,125.13,124.53,124.33,124.25,124.10,123.09,122.09,122.07,121.23,58.30,58.00$, $43.22,43.11,41.87,34.38,34.31,32.49,32.48,26.68,25.40,25.39,23.55,16.84,16.77$. MS (MALDI-TOF) $m / z(\%): 1176.6 .0$ $\left([\mathrm{M}-\mathrm{H}]^{+}, 100\right)$; HRMS ASAP ${ }^{+}$, calc for $\left[\mathrm{M}-\mathrm{CO}_{2} \mathrm{H}\right] \mathrm{C}_{81} \mathrm{H}_{87} \mathrm{~N}_{4} \mathrm{O}$ : 1131.6880 , Found: 1131.6842 ; IR (THF solution) $\mathrm{cm}^{-1}$; $3370(\mathrm{O}-$ $\mathrm{H}), 3500(\mathrm{O}-\mathrm{H}), 2217(\mathrm{C} \equiv \mathrm{N}), 1639(\mathrm{C}=\mathrm{O}), 1590(\mathrm{C}=\mathrm{N})$. 


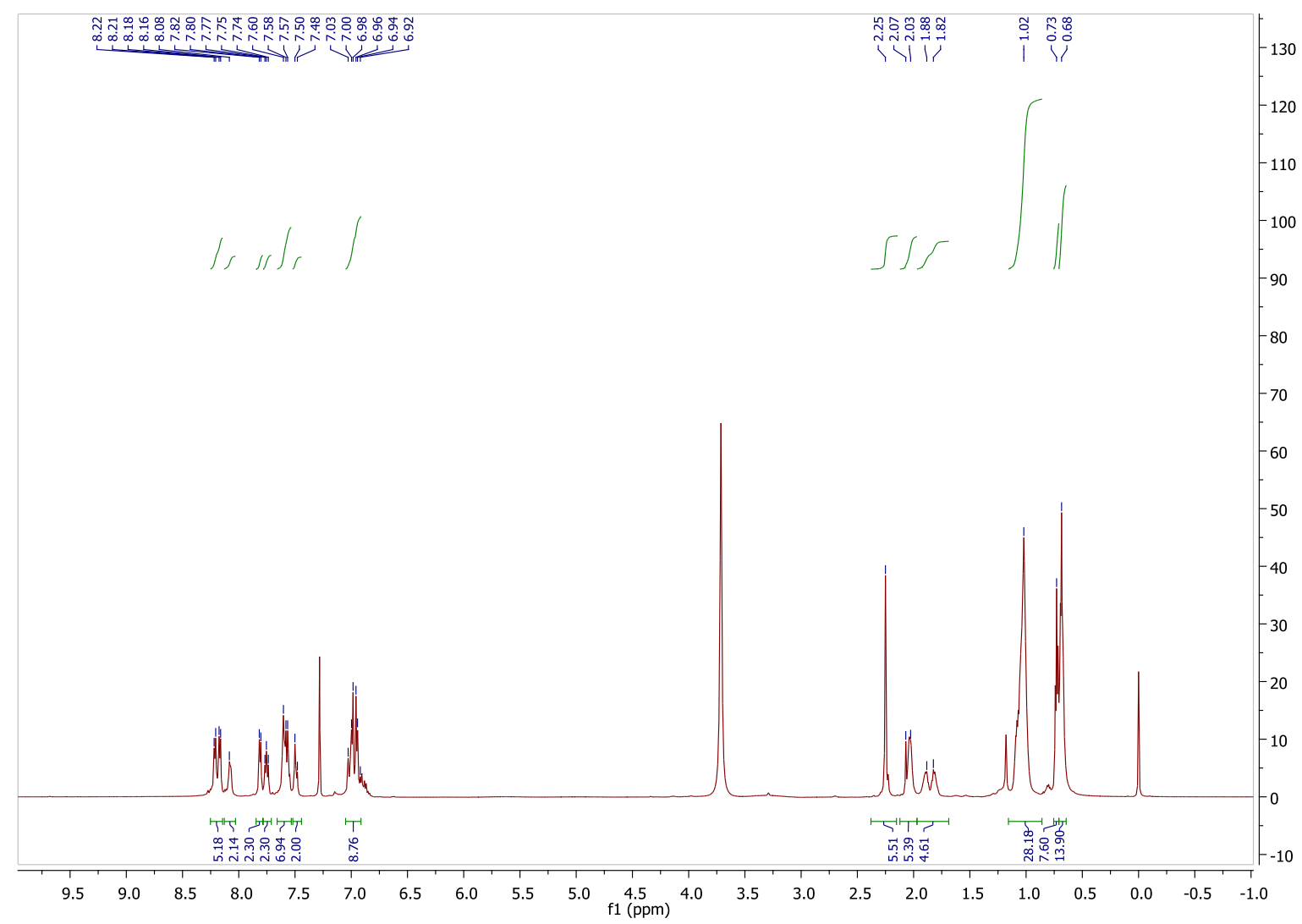

Figure S4. ${ }^{1} \mathrm{H}$ NMR spectrum of 3 in $\mathrm{CDCl}_{3} / \mathrm{CD}_{3} \mathrm{OD}$.

\section{References}

1 C. H. Chen, Y.-C. Hsu, H.-H. Chou, K. R. J. Thomas, J. T. Lin, C.-P. Hsu, Chem. Eur. J., 2010, 16, 3184.

2 K. E. Linton, A. L. Fisher, C. Pearson, M. A. Fox, L.-O. Palsson, M. R. Bryce, M. C. Petty, J. Mater. Chem., $2012,22,11816$. 